\title{
Uev1A Promotes Breast Cancer Cell Migration and EMT by Up-Regulating CT45A Expression via the AKT Pathway
}

\section{Tong Niu}

Capital Normal University

\section{Zhaojia Wu}

University of Saskatchewan

Wei Xiao ( $\square$ wei.xiao@usask.ca)

University of Saskatchewan https://orcid.org/0000-0001-7568-0782

\section{Research article}

Keywords: Uev1A, CT45A, AKT signaling pathway, NF-KB pathway, cell migration, EMT

Posted Date: December 10th, 2020

DOI: https://doi.org/10.21203/rs.3.rs-122157/v1

License: (c) (i) This work is licensed under a Creative Commons Attribution 4.0 International License.

Read Full License 


\section{Abstract}

Introduction

UEV1A encodes a ubiquitin-E2 variant closely associated with tumorigenesis and metastasis, but its underlying mechanism in promoting tumorigenesis remain to be investigated.

\section{Methods}

In this study, we experimentally manipulated UEV1A and CT45A gene expression and monitored their effects on cancer-related gene expression, cell migration and the signal transduction cascade.

Results

It was found that UEV1A overexpression induces CT45A family gene expression in breast cancer cells. Indeed, ectopic expression of UEV1A is sufficient to induce CT45A and its downstream genes involved in tumorigenesis, epithelial-mesenchymal transition (EMT), stemness and metastasis, and promote cell migration and EMT. Consistently, depletion of CT45A abolishes the above effects, indicating that CT45A is a critical downstream effector of Uev1A. The Uev1A-induced cell migration and EMT is dependent on AKT signaling but independent of NF-KB signaling, indicating that CT45A acts downstream of the AKT pathway.

\section{Conclusions}

Based on previous reports and observations in this study, we propose that the Ubc13-Uev1A complex activates AKT through K63-linked polyubiquitination, which leads to enhanced CT45A expression, stimulated cell migration and EMT. Since similar effects were also observed in a colorectal cancer cell line, we propose that the Ubc13/Uev1A-AKT-CT45A axis promotes tumorigenesis and metastasis in a broad range of tissues.

\section{Introduction}

UEV1, also known as CROC1 [1, 2] or CIR1 [3], was identified as a mammalian homolog of yeast MMS2 [4], as well as a potential proto-oncogene that is associated with tumorigenesis and metastasis [5-7]. Indeed, UEV1 maps to a region (chromosome 20q13.2) where DNA amplification is frequently reported in breast cancers [8-11] and other tumors [12]. Ubiquitin (Ub)-conjugating enzyme variant (UEV, including Mms2 or Uev1 in mammalian cells) is a co-factor of Ubc13 [13] and absolutely required for Ubc13mediated Lys63-linked polyubiquitin chain assembly [14-17]. To date, at least three UEV1 splicing variants have been reported, among which Uev1 A and Uev1C could promote K63-linked polyubiquitination by forming a complex with Ubc13 whereas Uev1B could not [18]. Uev1A differs from Uev1C in that it contains thirty additional amino acids at the $\mathrm{N}$-terminus $[18,19]$. 
Despite the fact that Uev1A and Mms2 are two major Uevs in mammalian cells and share a similar biochemical activity, they appear to function differently: Ubc13-Mms2 is required for DNA-damage response, whereas Ubc13-Uev1A is involved in NF-KB activation [18] and AKT activation [6]. Previous studies demonstrated that Uev1A-Ubc13 represses stress-induced apoptosis in HepG2 cells [20] and promotes breast and colon cancer metastasis through the NF-KB signaling pathway $[19,21]$. Meanwhile, Uev1A-Ubc13 promotes breast cancer cell survival and chemoresistance through the AKT pathway [6]. Consistently, chemical inhibition of the Uev1A-Ubc13 interaction suppresses cells survival and proliferation of diffuse large B-cell lymphoma cells [22]. These results collectively indicate that Uev1A is involved in tumorigenesis and metastasis.

The PI3K/AKT signaling pathway is an essential node in mammalian cells and is closely associated with various biological functions including cell growth, survival, proliferation, migration, resistance to apopotosis, differentiation, metabolism and angiogenesis [23-26]. In addition, this pathway is frequently found to be abnormally activated and altered in many human malignancies, which induces chemoresistance and malignant transformation [27-30].

In this study we found that overexpression of UEV1A induced CT45A expression in breast cancer cells in an Ubc13-dependent manner, while depletion of Uev1 inhibited CT45A expression. This study revealed that ectopic expression of CT45A could upregulate expression of its downstream genes related to tumorigenic, EMT, stemness and metastasis, and promote breast cancer EMT and cell migration. A series of experimental results support a notion that CT45A is a critical downstream gene of the AKT signaling pathway but not the NF-KB signaling pathway. Since similar effects were also observed in a colorectal cancer cell line, the Uev1A-/Ubc13-AKT-CT45A axis in tumorigenesis may be a general phenomenon. Hence, this study suggests a potential therapeutic target in the treatment of breast and colorectal cancers.

\section{Methods}

\section{Cell lines and culture}

Human breast cancer cell lines MCF7 and MDA-MB-231, and human colon carcinoma cell line HCT116 were obtained from the American Type Culture Collection (ATCC, Manassan, VA, USA). The cells were cultured in Dubecco's modified Eagle medium (DMEM, HyClone), supplemented with $10 \%$ fetal bovine serum (FBS, HyClone), 100 units/ml penicillin, and $100 \mu \mathrm{g} / \mathrm{ml}$ streptomycin (Invitrogen) at $37^{\circ} \mathrm{C}$ with $5 \%$ $\mathrm{CO}_{2}$. MDA-MB-231-TR and MCF7 UEV1A-overexpressed stable cell lines were created as previously reported [6]. MDA-MB-231 and MCF7 UEV1A-knockdown stable cell lines were created by transfecting MDA-MB-231 and MCF7 cells with UEV1A shRNA lentiviral particles or negative control shRNA lentiviral particles-A (Santa Cruz Biotechnology, Inc), and selecting with $1 \mu \mathrm{g} / \mathrm{ml}$ puromycin dihydrochloride (Santa Cruz Biotechnology, Inc).

\section{Plasmids and cell transfection}


Human UEV1A and CT45A open reading frames (ORFs) were amplified as Kphl-Xhol fragments and cloned into plasmid vector pcDNA4.0/TO/HA (+) as previously described [19]. The mutated Ubc13binding site (F38E) in UEV1A was designed based on a previous study with Mms2-F13E [17]. The CT45A small interfering RNA (siRNA) was purchased from GenePharma (Shanghai, China). The sequence for CT45A siRNA is 5'-GGAGAGAAAAGGAUCAGAUUU-3'. The modified sequence for UEV1A small hairpin RNA (shRNA, sc-38606-v) and negative control shRNA (sc-108080) delivered by lentiviral particles were obtained from Santa Cruz Biotechnology, Inc. The lentiviral particle infection of MDA-MB-231 and MCF7 breast cancer cells was performed following instructions of the supplier.

\section{RNA preparation and quantitative real-time RT-PCR (qRT-PCR)}

Total RNAs were extracted from cultured MDA-MB-231, MCF7 breast cancer and HCT116 colorectal cancer cells using Trizol (Invitrogen, 15596018). First-strand cDNA was synthesized with $1 \mu \mathrm{g}$ of total RNAs with TransScript ${ }^{\circledR}$ All-in-One First-Strand cDNA Synthesis SuperMix (TransGen, AT341-01) according to manufacturer's instructions. qRT-PCR analysis based on SYBR ${ }^{\circledR}$ Premix Ex Taq $^{\text {TM }}$ (Takara, RR420A) was performed on the BioRad real-time PCR machine. The specific primers are listed in Supplementary Table 1 . The data analysis was performed using the $2^{-\Delta C T}$ comparative cycle threshold method [31] from three independent experiments.

\section{Protein extraction and western blotting}

Cells were grown to log phase and lysed with whole-cell extraction buffer (150 mM NaCl; $1 \%$ NP-40; $10 \%$ glycerol; 1 mM EDTA; 50 mM Tris; 1 mM PMSF) and protease inhibitor cocktail for mammalian cells (Roche). Proteins in cell extracts were separated by $8-12 \%$ SDS-PAGE gels and transferred to PVDF membrane. The membrane was blocked with $5 \%$ milk/BSA and incubated with specific primary antibodies followed by secondary antibodies. The following antibodies were used: anti-AKT (\#4691, Cell Signaling Technology), anti-Phospho-Akt-Ser473 (\#4060, Cell Signaling Technology), anti-Phospho-AktTr308 (\#13038, Cell Signaling Technology), anti-Tubulin (sc-166729, Santa Cruz), anti-HA (A-190-208A. BETHYL), anti-N-cadherin (\#13116, Cell Signaling Technology), anti-E-cadherin (\#3195S, Cell Signaling Technology), anti-Lamin B (sc-6216, Santa Cruz), anti-NF-kB p65 (sc-8008, Santa Cruz), goat anti-mouse IgG-horseradish peroxidase (HRP) (sc-2005, Santa Cruz) and goat anti-rabbit IgG-HRP (sc-2004, Santa Cruz), donkey anti-goat lgG-HRP (sc-2033, Santa, Cruz).

\section{Cell migration assay}

In vitro cell migration ability was measured by a Transwell assay without Matrigel coating, using 8- $\mu$ mpore-size polycarbonate membrane filters in 24-well culture plates. After starving in FBS-free DMEM medium for 24 hours, $2 \times 10^{5}$ HCT116, $5 \times 10^{4}$ MDA-MB-231 and $2 \times 10^{5}$ MCF7 cells were seeded in the upper chamber, while the lower surface of the filter was coated with $10 \%$ FBS-DMEM as chemoattractants. The cells were allowed to migrate for 24 hours and the cells migrated to the lower surface of the filter were counted in five random fields under a light-microscope at high magnification. These experiments were done at least in triplicate. 


\section{Statistical analysis}

The statistical significance of differential findings between the control and experimental groups was determined by student's t-test as implemented by Microsoft Excel $2016\left({ }^{*}, P<0.05\right.$; $* \star P<0.01$; and $* \star \star, P$ $<0.001)$.

\section{Results}

\section{Uev1A upregulates $C T 45 A$ expression in a Ubc13-dependent manner}

We performed a microarray analysis by comparing UEV1A-overexpressed and vector control MDA-MB-231 breast cancer cells, which revealed 47 genes upregulated by more than fivefold in UEV1A-overexpressed MDA-MB-231 cells (Supplementary Table S2). Interestingly, 16 out of 47 belong to cancer/testis antigens (CTAs), among which CT45A family members are most highly elevated in UEV1A-overexpressed MDAMB-231 cells (Figure S1A). CTAs are tumor-associated and testis-derived specific immunogenic antigens closely associated with spontaneous immune responses in cancer patients [32,33]. They are not expressed in nearly all normal tissues except testis after birth, but are highly expressed in various types of cancers [34-39]. Within CTAs, the CT45A gene family comprises 10 genes designated as CT45A1 to CT45A10, which are distinct but highly conserved, as their amino-acid sequences exhibit more than $98 \%$ identity [40] (Figure S1B). To independently examine the role of Uev1A in upregulating CT45A expression and its biological implications, UEV1A was cloned into a pcDNA4.0/TO/HA(+) vector and then trasfected into MDA-MB-231-TR and MCF7 cells to construct stable cell lines as previously reported [19]. The level of UEV1A ectopic expression was monitored by western blot against the HA-tag after $10 \mu \mathrm{g} / \mathrm{ml}$ doxycyline (Dox) treatment (Figure S2A,B). Then CT45A expression was measured by qRT-PCR and found to be signifcantly upregulated in UEV1A-overexpressed MDA-MB-231-TR (Figure 1A) and MCF7 (Figure 1B) cells. It has been reported that UEV1A is upregulated in MDA-MB-231 and MCF7 cells by 2.8- and 4-fold, respectively [19]. To ask whether this moderate overexpression of UEV1A contributes to CT45A upregulation in breast cancer cells, we suppressed the endogenous UEV1A expression in MDA-MB-231 and MCF7 cells using shRNAs delivered by lentiviral particles as previously reported [19]. It was found that two independent shUEV1A constructs, shUEV1A-1 and shUEV1A-2, reduced UEV1A expression in MDA-MB-231 cells by $43 \%$ and $60 \%$ (Figure S3A), and in MCF7 cells by $71 \%$ and $85 \%$ (Figure S3B), respectively, compared to contral shRNA-treated cells. Meanwhile, the CT45A transcript levels were also reduced (Figure 1C, D). To further ask whether Uev1A upregulates CT45A expression in a Ubc13dependent manner, we constructed stable MDA-MB-231-TR and MCF7 cell lines expressing Dox-inducible Uev1A-F38E mutant protein (Figure S2A,B), which is known to abolish physical interaction between Mms2/Uev1A and Ubc13 $[7,17,19]$. As expected, UEV1A-F38E failed to upregulate CT45A mRNA levels in both MDA-MB-231-TR (Figure 1E) and MCF7 (Figure 1F) cells. These observations collectively indicate that Uev1A upregulates CT45A expression in a Ubc13-dependent manner in breast cancer cells.

\section{Uev1A positively regulates $C T 45 A$ downstream gene expression in breast cancer cells}


CT45A has been reported to act as a proto-oncogene through upregulating tumorigenic and metastatic genes [41]. We first measured the transcript level of several CT45A previously-reported [41] downstream genes thought to be involved in tumoregenesis, EMT, stemness and metastasis after CT45A ectopic expression. The expression of some tumoregenesis-associated genes, including those encoding RAS exchange factor (RASGEF1A), melanoma antigen family member (MAGED4B), homeobox B6 (HOXB6 and HOXD13) was indeed significantly higher in CT45A-overexpressed MDA-MB-231 (Figure 2A) and MCF7 (Figure 2B) cells than their respective control cells. Expression of several EMT, stemness and metastasis related genes, including TWIST1, KIT, aldehyde dehydrogenase 1 family, member A1 (ALDH1A1), CXCR4 and/or SULF2 were also upregulated in CT45A-overexpressed MDA-MB-231 (Figure 2C) and MCF7 (Figure 2D) cells. Since UEV1A can upregulate CT45A expression, we asked whether UEV1A could also upregulate the expression of $C T 45 A$ downstream genes in breast cancer cells. Indeed, the majority of CT45A downstream genes, including HOXB6, HOXD13, RASGEF1A, MAGED4B, ALDH1A1, TWIST1, KIT, CXCR4 and SULF2, were upregulated in UEV1A-overexpressed MDA-MB-231 (Figure 2E, G) and MCF7 (Figure 2F, H) cells. Taken together, we conclude that UEV1A positively regulates CT45A downstream gene expression in breast cancer cells.

\section{CT45A is a critical regulator for Uev1A-induced breast cancer cell migration}

To ask whether an elevated CT45A level alone is indeed sufficient to promote breast cancer development and metastasis, CT45A was cloned into plasmid pcDNA4.0/TO/HA(+), transiently transfected into MDAMB-231 and MCF7 cells and the level of CT45A ectopic expression after $200 \mu \mathrm{g} / \mathrm{ml}$ zeocin treatment was monitored by western blot against an HA-tag antibody (Figures $3 \mathrm{~A}$ and $4 \mathrm{~A}$ ). The effects of CT45A ectopic expression on MDA-MB-231 (Figure 3) and MCF7 (Figure 4) cells were then assessed. The transwell without matrigel experiments show that overexpression of CT45A nearly tripled the MDA-MB-231 cell mobility compared with vector-transfected cells (Figure 3B,C). Similarly, after induction the migration of MCF7 CT45A transfectants was more than 2.3-fold higher than the control cells (Figure 4B,C), indicating that $\mathrm{CT} 45 \mathrm{~A}$ regulates breast cancer cell migration in vitro.

To ask whether Uev1A is a critical regulator for CT45A-induced migration, we successfully depleted CT45A by approximately 50\% using siRNA in MDA-MB-231 (Figure S3C) and MCF7 (Figure S3D) cells. Similar effects were also observed in UEV1A-overexpressed MDA-MB-231 (Figure 3D) and MCF7 (Figure 4D) cells. The above treatment does not affect the expression of UEV1A (Figures $3 \mathrm{E}$ and $4 \mathrm{E}$ ), but the moderate CT45A depletion in UEV1A-overexpressed cells markedly reduced cell migration as determined by a transwell assay without matrigel (Figures $3 F, G$ and $4 F, G$ ). The above findings allow us to conclude that CT45A is a critical regulator for Uev1A-induced migration in breast cancer cells, as partial depletion of CT45A can reverse cell migration in UEV1A-overexpressed breast cancer cells.

\section{CT45A promotes metastasis in other type of cancer cells}

To ask whether UEV1A overexpression also increases CT45A expression in other cancer cells, we created stable UEV1A-transfected HCT116 colorectal cancer cell lines as previously described (Figure 5A) [21], in which CT45A was moderately upregulated upon UEV1A ectopic expression, and this upregulation was not 
observed in the UEV1A-F38E-expressed HCT116 cells (Figure 5B). To ask whether this moderate overexpression of UEV1A contributes to CT45A upregulation in colorectal cancer cells, we suppressed the endogenous UEV1A expression in HCT116 cells by using shRNAs delivered by lentiviral particles as previously reported [21]. It was found that two independent shUEV1A constructs, shUEV1A-1 and shUEV1A-2, reduced UEV1A expression in HCT116 cells by $55 \%$ and $65 \%$, respectively (Figure S4A), compared to control shRNA-treated cells. Meanwhile, the CT45A transcript levels were also reduced (Figure 5C). To ask whether ectopic expression of CT45A could promote metastasis in other types of cancer cells, HCT116 cells were transiently transfected with pcDNA4.0/TO/HA-CT45A and the CT45A expression was monitored by western blot analysis against HA-tagged CT45A (Figure 5D). The CT45A ectopic expression resulted in concommitant increase in HCT116 cell migration by sevenfold (Figure $5 \mathrm{E}, \mathrm{F})$, indicating that CT45A could also promote tumorigenesis and metastasis in other types of cancer cells. To further ask whether CT45A is a critical regulator for UEV1A-induced migration, we depleted CT45A by using siRNA in UEV1A-overexpressed HCT116 cells. As shown in Figure S4B, CT45A was depleted by $44 \%$. The above treatment does not affect the expression of UEV1A (Figure S4C), but the moderate CT45A depletion in UEV1A-overexpressed HCT116 cells markedly reduced cell migration as determined by a transwell assay without matrigel (Figure $5 \mathrm{G}, \mathrm{H}$ ). The above findings indicate that Uev $1 \mathrm{~A}$ induces colorectal cancer cell migration through upregulating CT45A genes.

\section{Depletion of CT45A can reverse EMT in UEV1Aoverexpressed breast cancer cells}

Epithelial-mesenchymal transition (EMT) is closely associated with cancer progression, cancer cell metastasis and drug resistance $[42,43]$. Cells undergoing EMT display increased expression of mesenchymal genes including $\mathrm{N}$-cadherin, fibronectin and vimentin, and decreased expression of epithelial genes including E-cadherin, occulin and ZO-1 [44]. It was reported that overexpression of CT45A could induce breast cancer EMT, and thus foster cancer metastasis by upregulating EMT master gene TWIST1 [41]. To further investigate the potential molecular mechanisms by which CT45A regulates breast cancer cell migration, we monitored alterations of EMT markers, including $\mathrm{N}$-cadherin and vimentin, two well-characterized mesenchymal markers, and E-cadherin, a well-known epithelial marker [44, 45]. Consistent with breast cancer cell migration, increased mRNA levels of $\mathrm{N}$-cadherin and vimentin and decreased E-cadherin were found upon CT45A overexpression in MDA-MB-231 (Figure 6A) and MCF7 (Figure 6B) cells. We also assessed the effect of CT45A on cellular N-cadherin and E-cadherin at protein levels. Firstly, we monitored cellular N-cadherin and E-cadherin levels in MDA-MB-231 and MCF7 cells and found that MDA-MB-231 and MCF7 cells produced detectable N-cadherin and E-cadherin, respectively (Figure 6C). Interestingly, ectopic expression of CT45A increased N-cadherin in MDA-MB-231 cells and decreased E-cadherin in MCF7 cells (Figure 6C,E,F), suggesting that cell migration stimulated by ectopic CT45A expression is likely due to the enhanced EMT in breast cancer cells. To address whether Uev1A is a critical upstream regulator of CT45A-induced EMT, we depleted CT45A by using siRNA in UEV1Aoverexpressed MDA-MB-231 and MCF7 breast cancer cells (Figures 3D and 4D), which significantly increased E-cadherin protein levels in UEV1A-overexpressed MCF7 cells and decreased $\mathrm{N}$-cadherin protein levels in UEV1A-overexpressed MDA-MB-231 cells (Figure 6D,G,H). Collectively, these results support a notion that Uev1A can serve as an important regulator for CT45A-induced EMT in breast cancer cells. 


\section{Uev1A regulates $C T 45 A$ expression through the AKT signaling pathway}

Since Uev1A has been reported to be associated with NF-KB activation [19-21] and AKT activation [6], we wish to investigate molecular mechanisms by which Uev1 A regulates $C T 45 \mathrm{~A}$ expression. To ask whether Uev1A regulates $C T 45 A$ expression through the NF-KB pathway, MDA-MB-231 and HCT116 cells transiently overexpressing UEV1A were treated with the NF-KB pathway inhibitor Bay11-7082 [46] and its efficacy was measured by the nuclear P65 level (Figure S5A,C). The CT45A transcript level was not significantly reduced in UEV1A-ovexpressed MDA-MB-231 (Figure S5B) and HCT116 cells (Figure S5D) by treatment with Bay11-7082, indicating that Uev1A upregulation of CT45A expression is independent of the NF-KB pathway. To ask whether Uev1A regulates CT45A expression through the AKT signaling pathway in breast cancer cells, phosphorylation levels of both AKT-Thr308 and AKT-Ser473 in MDA-MB231 and MCF7 cells transiently overexpressing UEV1A were first monitored by western blot and found to be increased (Figure 7A). In contrast, overexpression of UEV1A-F38E failed to induce AKT phosphorylation at both residues (Figure 7A), indicating that the effects of Uev1A on AKT is dependent on its interaction with Ubc13. These observations allow us to conclude that excessive Uev1A promotes the Uev1A-Ubc13 complex formation, which activates the AKT signaling pathway. To further address whether Uev1A promotes CT45A expression through the AKT signaling pathway, we examined effects of PI3K/AKT pathway inhibitor LY294002 [47] on MDA-MB-231 and MCF7 cells with ectopic UEV1A expression. As seen in Figure 7B, the AKT-Ser473 phosphorylation level was markedly decreased after LY294002 treatment in UEV1A-overexpressed MDA-MB-231 and MCF7 cells compared to those without the inhibitor treatment. We then examined CT45A expression and found that, compared to cells without LY294002 treatment, the CT45A transcript level was significantly reduced in UEV1A-overexpressed MDAMB-231 (Figure 7C) and MCF7 (Figure 7D) cells after $10 \mu \mathrm{M}$ LY294002 treatment. After $20 \mu \mathrm{M}$ LY294002 treatment, the CT45A transcript further decreased to levels below the vector control cells without the inhibitor treatment (Figure 7C,D). It was previously reported that insulin-like growth factor (IGF-1) is an important activator of the PI3K/AKT signaling pathway $[48,49]$. To further investigate whether CT45A is indeed a direct downstream gene of the AKT signaling pathway, we treated MDA-MB-231 (Figure 7E) and MCF7 (Figure 7F) cells with IGF-1, and found that the AKT-Ser473 phosphorylation level was dramatically increased after IGF-1 treatment compared to untreated cells. Under the above experimental conditions, the CT45A mRNA levels were significantly increased in MDA-MB-231 (Figure 7G) and MCF7 (Figure 7H) cells after IGF-1 treatment. Collectively, we conclude that Uev1A-Ubc13 regulates CT45A expression through the AKT signaling pathway in breast cancer cells.

\section{Discussion}

Previous reports have identified CT45A as a chemosensitivity mediator and immunotherapy target in ovarian cancer $[40,50]$. In addion, CT45A has no detectable expression in normal tissues after birth, except for the testis, but it is closely associated with the progression and development of various cancers [41, 51-54]. In particular, it is highly expressed in cancer stem cells (CSCs), but not in differentiated cells [55], indicating that it is a promising biomarker for diagnosis and treatment of cancer patients. However, exactly how the CT45A family genes function in these processes remain unclear. 
The CT45A family genes were brought to our attention based on our preliminary microarray data from which CT45A family genes were among the highest induced genes following UEV1A overexpression in MDA-MB-231 breast cancer cells. This obervation was independently confirmed in two breast cancer cell lines, although the levels of CT45A induction after UEV1A overexpression vary. In this study, we first investigated the correlation between CT45A and tumorigenesis using breast cancer cell models. At the beginning of our investigation, the CT45A gene family was thought to comprise six members (CT45A7CT45A6) and their amino-acid sequences share more than $98 \%$ identity; hence we cloned one of them (CT45A7) to represent all members. Consistantly, siRNAs used in this study were designed to target all six CT45A family genes. Recently, the CT45A family has been updated to 10 genes in NCBI, and their aminoacid sequences still share more than $98 \%$ identity [40], making our initial experimental designs still valid. We overexpressed CT45A in MDA-MB-231 and MCF7 breast cancer cells and found that CT45A could promote cell migration, EMT and its downstream tumorigenic, EMT, stemness and metastatis related genes expression, indicating that CT45A plays an important role in breast cancer tumorigenesis.

A previous study showed that CT45A protein has a DEAD/H box which has RNA helicase activity and putative nucleic acid binding function [41]. RNA helicases of DEAD box family are required for gene expression and transcrition by interacting with RNA polymerase II (Pol II ) [56], whether CT45A interacts with RNA Pol II or other transcription factors to promote tumorigenesis and metastasis remains to be further elucidated.

This study investigated the correlation between Uev1A and CT45A in breast cancer cell migartion and EMT. It was found that Uev1A upregulates CT45A expression in a Ubc13-dependent manner in one colorectal cancer and two breast cancer cell lines. In a reverse expreriment, depletion of UEV1A in the above three cancer cell lines significantly inhibited the upregulation of CT45A, indicating that Uev1 A plays a critical role in the upregulation of CT45A. Siminarly, Uev1A positively regulates the expression of CT45A downstream tumorigenic, EMT, stemness and metastatis related genes in breast cancer cells. Moreover, under our experimental conditions, we found that $\mathrm{N}$-cadherin was readily detectable in MDAMB-231 but not MCF7 cells, while E-cadherin was detected in MCF7 but not MDA-MB-231 cells. Furthermore, ectopic expression of CT45A could increase N-cadherin in MDA-MB-231 cells and decrease E-cadherin in MCF7 cells, both of which are expected to promote tumorigenesis. Indeed, CT45A depletion in UEV1A-overexpressed cells reduced EMT and cell migration to a level comparable to that of controltransfected cells. These findings together indicate that Uev1A is a critical regulator of CT45A-induced cell migration and EMT in breast cancer.

In order to determine through which signaling pathway(s) Uev1A upregulates CT45A expression, we treated UEV1A ectopic expression cells with NF-KB and PI3K/AKT pathway inhibitors and found that inhibition of AKT markedly decreased CT45A expression, while inhibition of NF-KB activity had no observable effects. To further confirm that CT45A is a direct downstream gene of the AKT pathway, we treated breast cancer cells with the AKT pathway activator IGF- 1 and found that the IGF- 1 treatment leads to $C T 45 A$ induction. The AKT signaling pathway is closely associated with many biological processes such as cell proliferation, migration and differentiation [24]. It has been reported that AKT undergoes the 
TRAF6-triggered K63-linked polyubiquitination, which is critical for AKT membrane localization, phosphorylation and subsequent activation $[57,58]$. Since Uev1A-Ubc13 is the only known E2 complex to regulate K63-linked polyubiquitination leading to the AKT pathway activation in breast cancer [6], this study reveals a novel Uev1A/Ubc13-AKT-CT45A axis to promote breast cancer cell migration and EMT (Figure 8). Given limited but consistent observations in a colorectal cancer cell line, the above signaling cascade may be expanded to other types of cancers.

\section{Conclusions}

Overexpression of UEV1A is sufficient to activate the AKT pathway in breast cancer cell lines, which in turn upregulates CT45A expression to promote breast cancer cell migration and EMT. These observations provide a potential therapeutic target in the treatment of breast cancer.

\section{Abbreviations}

CTA: cancer/testis antigen; DMEM: Dubecco's modified Eagle medium; Dox: doxycycline; EMT: epithelialmesenchymal transition; FBS: fetal bovine serum; IGF: insulin-like growth factor; ORF: open reading frame; qRT-PCR: real-time reverse-transcription PCR; Ub: ubiquitin; UEV: Ubiquitin-conjugating enzyme variant.

\section{Declarations}

\section{Ethics Approval and consent to participate}

Not applicable

Consent for Publication

All authors agree with the the final version of the manuscript.

\section{Availability of supporting data}

Available upon request

\section{Competing interests}

The authors declare they have no competing interests.

\section{Funding}

This work was supported by a Capital Normal University Specia fund and the Canadian Breast Cancer Foundation research grant $\mathrm{C7022}$ to WX. TN received a Capital Normal University visiting studentship.

\section{Authors' contributions}


TN and ZW participated in the project design and carried out all experiments. TN wrote the initial draft manuscript. WX conceived the study, participated in the project design, manuscript preparation and submission. All aothors read and approved the final manuscript.

\section{Acknowledgements}

The authors wish to thank mambers of the Xiao laboratory for helpful discussion and Michelle Hanna for proofreading the manuscript.

\section{References}

1. Rothofsky ML, Lin SL: CROC-1 encodes a protein which mediates transcriptional activation of the human FOS promoter. Gene 1997, 195(2):141-149.

2. Franko J, Ashley C, Xiao W: Molecular cloning and functional characterization of two murine cDNAs which encode Ubc variants involved in DNA repair and mutagenesis. Biochim Biophys Acta 2001, 1519(1-2):70-77.

3. Ma L, Broomfield S, Lavery C, Lin SL, Xiao W, Bacchetti S: Up-regulation of CIR1/CROC1 expression upon cell immortalization and in tumor-derived human cell lines. Oncogene 1998, 17(10):1321-1326.

4. Xiao W, Lin SL, Broomfield S, Chow BL, Wei YF: The products of the yeast MMS2 and two human homologs (hMMS2 and CROC-1) define a structurally and functionally conserved Ubc-like protein family. Nucleic Acids Res 1998, 26(17):3908-3914.

5. Sancho E, Vilá MR, Sánchez-Pulido L, Lozano JJ, Paciucci R, Nadal M, Fox M, Harvey C, Bercovich B, Loukili $\mathrm{N}$ et al: Role of UEV-1, an inactive variant of the E2 ubiquitin-conjugating enzymes, in in vitro differentiation and cell cycle behavior of HT-29-M6 intestinal mucosecretory cells. Mol Cell Bio/ 1998, 18(1):576-589.

6. Wu Z, Niu T, Xiao W: Uev1A promotes breast cancer cell survival and chemoresistance through the AKT-FOXO1-BIM pathway. Cancer Cell Int 2019, 19:331.

7. Zhang W, Zhuang Y, Zhang Y, Yang X, Zhang H, Wang G, Yin W, Wang R, Zhang Z, Xiao W: Uev1A facilitates osteosarcoma differentiation by promoting Smurf1-mediated Smad1 ubiquitination and degradation. Cell Death Dis 2017, 8(8):e2974.

8. Brinkmann U, Gallo M, Polymeropoulos MH, Pastan I: The human CAS (cellular apoptosis susceptibility) gene mapping on chromosome $20 q 13$ is amplified in BT474 breast cancer cells and part of aberrant chromosomes in breast and colon cancer cell lines. Genome Res 1996, 6(3):187-194.

9. Kallioniemi A, Kallioniemi OP, Piper J, Tanner M, Stokke T, Chen L, Smith HS, Pinkel D, Gray JW, Waldman FM: Detection and mapping of amplified DNA sequences in breast cancer by comparative genomic hybridization. Proc Natl Acad Sci U S A 1994, 91(6):2156-2160.

10. Tanner MM, Tirkkonen M, Kallioniemi A, Collins C, Stokke T, Karhu R, Kowbel D, Shadravan F, Hintz M, Kuo WL et al: Increased copy number at 20q13 in breast cancer: defining the critical region and exclusion of candidate genes. Cancer Res 1994, 54(16):4257-4260. 
11. Tanner MM, Tirkkonen M, Kallioniemi A, Holli K, Collins C, Kowbel D, Gray JW, Kallioniemi OP, Isola J: Amplification of chromosomal region $20 \mathrm{q} 13$ in invasive breast cancer: prognostic implications. Clin Cancer Res 1995, 1(12):1455-1461.

12. El-Rifai W, Harper JC, Cummings OW, Hyytinen ER, Frierson HF, Jr., Knuutila S, Powell SM: Consistent genetic alterations in xenografts of proximal stomach and gastro-esophageal junction adenocarcinomas. Cancer Res 1998, 58(1):34-37.

13. Hofmann RM, Pickart CM: Noncanonical MMS2-encoded ubiquitin-conjugating enzyme functions in assembly of novel polyubiquitin chains for DNA repair. Cell 1999, 96(5):645-653.

14. McKenna S, Moraes T, Pastushok L, Ptak C, Xiao W, Spyracopoulos L, Ellison MJ: An NMR-based model of the ubiquitin-bound human ubiquitin conjugation complex Mms2.Ubc13. The structural basis for lysine 63 chain catalysis. J Biol Chem 2003, 278(15):13151-13158.

15. McKenna S, Spyracopoulos L, Moraes T, Pastushok L, Ptak C, Xiao W, Ellison MJ: Noncovalent interaction between ubiquitin and the human DNA repair protein Mms2 is required for Ubc13mediated polyubiquitination. J Biol Chem 2001, 276(43):40120-40126.

16. Moraes TF, Edwards RA, McKenna S, Pastushok L, Xiao W, Glover JN, Ellison MJ: Crystal structure of the human ubiquitin conjugating enzyme complex, hMms2-hUbc13. Nat Struct Biol 2001, 8(8):669673.

17. Pastushok L, Moraes TF, Ellison MJ, Xiao W: A single Mms2 "key" residue insertion into a Ubc13 pocket determines the interface specificity of a human Lys63 ubiquitin conjugation complex. $J$ Biol Chem 2005, 280(18):17891-17900.

18. Andersen PL, Zhou H, Pastushok L, Moraes T, McKenna S, Ziola B, Ellison MJ, Dixit VM, Xiao W: Distinct regulation of Ubc13 functions by the two ubiquitin-conjugating enzyme variants Mms2 and Uev1A. J Cell Biol 2005, 170(5):745-755.

19. Wu Z, Shen S, Zhang Z, Zhang W, Xiao W: Ubiquitin-conjugating enzyme complex Uev1A-Ubc13 promotes breast cancer metastasis through nuclear factor-KB mediated matrix metalloproteinase-1 gene regulation. Breast Cancer Res 2014, 16(4):R75.

20. Syed NA, Andersen PL, Warrington RC, Xiao W: Uev1A, a ubiquitin conjugating enzyme variant, inhibits stress-induced apoptosis through NF-kappaB activation. Apoptosis 2006, 11(12):2147-2157.

21. Wu Z, Neufeld H, Torlakovic E, Xiao W: Uev1A-Ubc13 promotes colorectal cancer metastasis through regulating CXCL1 expression via NF-KB activation. Oncotarget 2018, 9(22):15952-15967.

22. Pulvino M, Liang Y, Oleksyn D, DeRan M, Van Pelt E, Shapiro J, Sanz I, Chen L, Zhao J: Inhibition of proliferation and survival of diffuse large B-cell lymphoma cells by a small-molecule inhibitor of the ubiquitin-conjugating enzyme Ubc13-Uev1A. Blood 2012, 120(8):1668-1677.

23. Karar J, Maity A: PI3K/AKT/mTOR pathway in angiogenesis. Front Mol Neurosci 2011, 4:51.

24. Pompura SL, Dominguez-Villar M: The PI3K/AKT signaling pathway in regulatory T-cell development, stability, and function. J Leukoc Biol 2018, 103:1065-1076.

25. Bader AG, Kang S, Zhao L, Vogt PK: Oncogenic PI3K deregulates transcription and translation. Nat Rev Cancer 2005, 5(12):921-929. 
26. Yang J, Pi C, Wang G: Inhibition of PI3K/Akt/mTOR pathway by apigenin induces apoptosis and autophagy in hepatocellular carcinoma cells. Biomed Pharmacother 2018, 103:699-707.

27. Fresno Vara JA, Casado E, de Castro J, Cejas P, Belda-Iniesta C, González-Barón M: PI3K/Akt signalling pathway and cancer. Cancer Treat Rev 2004, 30(2):193-204.

28. Kim D, Dan HC, Park S, Yang L, Liu Q, Kaneko S, Ning J, He L, Yang H, Sun M et al: AKT/PKB signaling mechanisms in cancer and chemoresistance. Front Biosci 2005, 10:975-987.

29. Sun M, Paciga JE, Feldman RI, Yuan Z, Coppola D, Lu YY, Shelley SA, Nicosia SV, Cheng JQ: Phosphatidylinositol-3-OH Kinase (PI3K)/AKT2, activated in breast cancer, regulates and is induced by estrogen receptor alpha (ERalpha) via interaction between ERalpha and PI3K. Cancer Res 2001, 61(16):5985-5991.

30. Brognard J, Clark AS, Ni Y, Dennis PA: Akt/protein kinase B is constitutively active in non-small cell lung cancer cells and promotes cellular survival and resistance to chemotherapy and radiation. Cancer Res 2001, 61(10):3986-3997.

31. Livak KJ, Schmittgen TD: Analysis of relative gene expression data using real-time quantitative PCR and the 2(-Delta Delta C(T)) Method. Methods 2001, 25(4):402-408.

32. van der Bruggen $P$, Traversari C, Chomez P, Lurquin C, De Plaen E, Van den Eynde BJ, Knuth A, Boon $\mathrm{T}$ : A gene encoding an antigen recognized by cytolytic T lymphocytes on a human melanoma. $J$ Immunol 2007, 178(5):2617-2621.

33. Chen YT, Boyer AD, Viars CS, Tsang S, Old LJ, Arden KC: Genomic cloning and localization of CTAG, a gene encoding an autoimmunogenic cancer-testis antigen NY-ESO-1, to human chromosome Xq28. Cytogenet Cell Genet 1997, 79(3-4):237-240.

34. Whitehurst AW: Cause and consequence of cancer/testis antigen activation in cancer. Annu Rev Pharmacol Toxicol 2014, 54:251-272.

35. John T, Starmans MH, Chen YT, Russell PA, Barnett SA, White SC, Mitchell PL, Walkiewicz M, Azad A, Lambin $\mathrm{P}$ et al: The role of cancer-testis antigens as predictive and prognostic markers in non-small cell lung cancer. PLoS One 2013, 8(7):e67876.

36. Pandey A, Kurup A, Shrivastava A, Radhi S, Nguyen DD, Arentz C, D'Chuna N, Hardwick F, D'Souza $M J$, Jenkins $M$ et al: Cancer testes antigens in breast cancer: biological role, regulation, and therapeutic applicability. Int/ Rev Immuno/ 2012, 31(5):302-320.

37. Chen Z, Li M, Yuan Y, Wang Q, Yan L, Gu J: Cancer/testis antigens and clinical risk factors for liver metastasis of colorectal cancer: a predictive panel. Diseases Colon Rectum 2010, 53(1):31-38.

38. Shiraishi T, Terada N, Zeng Y, Suyama T, Luo J, Trock B, Kulkarni P, Getzenberg RH: Cancer/testis antigens as potential predictors of biochemical recurrence of prostate cancer following radical prostatectomy. J Translational Med 2011, 9:153.

39. Inaoka RJ, Jungbluth AA, Gnjatic S, Ritter E, Hanson NC, Frosina D, Tassello J, Etto LY, Bortoluzzo AB, Alves AC et al: Cancer/testis antigens expression and autologous serological response in a set of Brazilian non-Hodgkin's lymphoma patients. Cancer Immunol Immunother 2012, 61(12):2207-2214. 
40. Coscia F, Lengyel E, Duraiswamy J, Ashcroft B, Bassani-Sternberg M, Wierer M, Johnson A, Wroblewski K, Montag A, Yamada SD et al: Multi-level proteomics identifies CT45 as a chemosensitivity mediator and immunotherapy target in ovarian cancer. Cel/ 2018, 175(1):159170.e116.

41. Shang B, Gao A, Pan Y, Zhang G, Tu J, Zhou Y, Yang P, Cao Z, Wei Q, Ding Y et al: CT45A1 acts as a new proto-oncogene to trigger tumorigenesis and cancer metastasis. Cell Death \& Disease 2014, 5(6):e1285.

42. Thiery JP: Epithelial-mesenchymal transitions in development and pathologies. Curr Opin Cell Biol 2003, 15(6):740-746.

43. Du B, Shim JS: Targeting epithelial-mesenchymal transition (EMT) to overcome drug resistance in cancer. Molecules 2016, 21(7):965.

44. Lamouille S, Xu J, Derynck R: Molecular mechanisms of epithelial-mesenchymal transition. Nat Rev Mol Cell Biol 2014, 15(3):178-196.

45. Gonzalez DM, Medici D: Signaling mechanisms of the epithelial-mesenchymal transition. Sci Signaling 2014, 7(344):re8.

46. Pierce JW, Schoenleber R, Jesmok G, Best J, Moore SA, Collins T, Gerritsen ME: Novel inhibitors of cytokine-induced IkappaBalpha phosphorylation and endothelial cell adhesion molecule expression show anti-inflammatory effects in vivo. J Biol Chem 1997, 272(34):21096-21103.

47. Anas MK, Shimada M, Terada T: Possible role for phosphatidylinositol 3-kinase in regulating meiotic maturation of bovine oocytes in vitro. Theriogenol 1998, 50(3):347-356.

48. Zhu C, Qi X, Chen Y, Sun B, Dai Y, Gu Y: PI3K/Akt and MAPK/ERK1/2 signaling pathways are involved in IGF-1-induced VEGF-C upregulation in breast cancer. J Cancer Res Clin Oncol 2011, 137(11):15871594.

49. Yang $L$, Wang $H$, Liu L, Xie A: The role of insulin/IGF-1/PI3K/Akt/GSK3 $\beta$ signaling in parkinson's disease dementia. Front Neurosci 2018, 12:73.

50. Reed E, Ozols RF, Tarone R, Yuspa SH, Poirier MC: Platinum-DNA adducts in leukocyte DNA correlate with disease response in ovarian cancer patients receiving platinum-based chemotherapy. Proc Nat Acad Sci U S A 1987, 84(14):5024-5028.

51. Zhang W, Barger CJ, Link PA, Mhawech-Fauceglia P, Miller A, Akers SN, Odunsi K, Karpf AR: DNA hypomethylation-mediated activation of Cancer/Testis Antigen 45 (CT45) genes is associated with disease progression and reduced survival in epithelial ovarian cancer. Epigenet 2015, 10(8):736-748.

52. Piotti KC, Scognamiglio T, Chiu R, Chen YT: Expression of cancer/testis (CT) antigens in squamous cell carcinoma of the head and neck: evaluation as markers of squamous dysplasia. Pathol Res Pract 2013, 209(11):721-726.

53. Koop A, Sellami N, Adam-Klages S, Lettau M, Kabelitz D, Janssen O, Heidebrecht HJ: Down-regulation of the cancer/testis antigen 45 (CT45) is associated with altered tumor cell morphology, adhesion and migration. Cell Commun Signaling 2013, 11(1):41. 
54. Chen YT, Hsu M, Lee P, Shin SJ, Mhawech-Fauceglia P, Odunsi K, Altorki NK, Song CJ, Jin BQ, Simpson AJ et al: Cancer/testis antigen CT45: analysis of mRNA and protein expression in human cancer. Intl J Cancer 2009, 124(12):2893-2898.

55. Yamada R, Takahashi A, Torigoe T, Morita R, Tamura Y, Tsukahara T, Kanaseki T, Kubo T, Watarai K, Kondo $\mathrm{T}$ et al: Preferential expression of cancer/testis genes in cancer stem-like cells: proposal of a novel sub-category, cancer/testis/stem gene. Tissue Antigens 2013, 81(6):428-434.

56. Linder P, Jankowsky E: From unwinding to clamping - the DEAD box RNA helicase family. Nat Rev Mol Cell Biol 2011, 12(8):505-516.

57. Yang WL, Wang J, Chan CH, Lee SW, Campos AD, Lamothe B, Hur L, Grabiner BC, Lin X, Darnay BG et al: The E3 ligase TRAF6 regulates Akt ubiquitination and activation. Science 2009, 325(5944):11341138.

58. Yang WL, Wu CY, Wu J, Lin HK: Regulation of Akt signaling activation by ubiquitination. Cell Cycle 2010, 9(3):487-497.

\section{Figures}


A

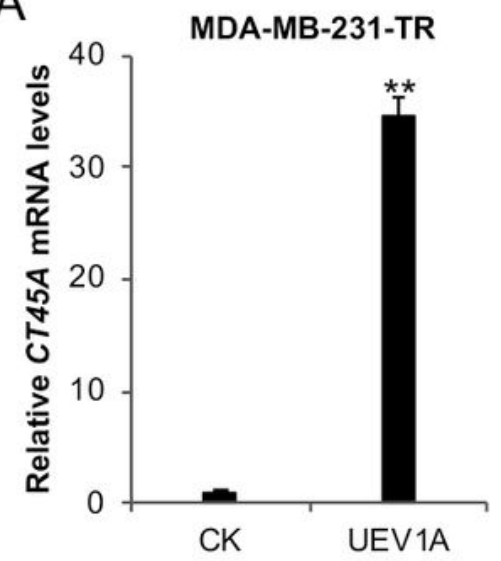

C

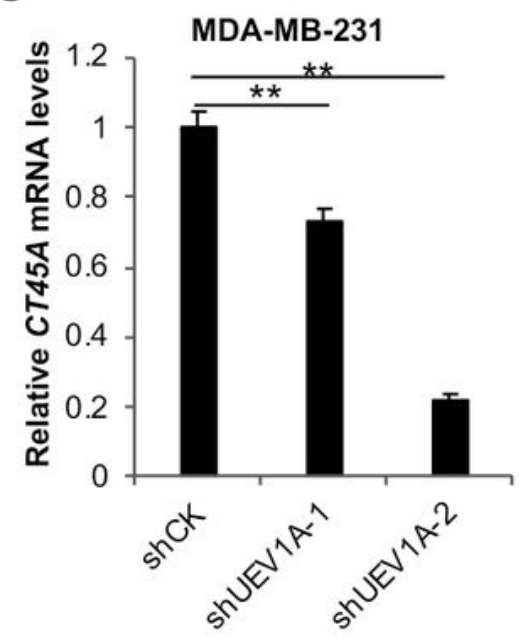

$E$

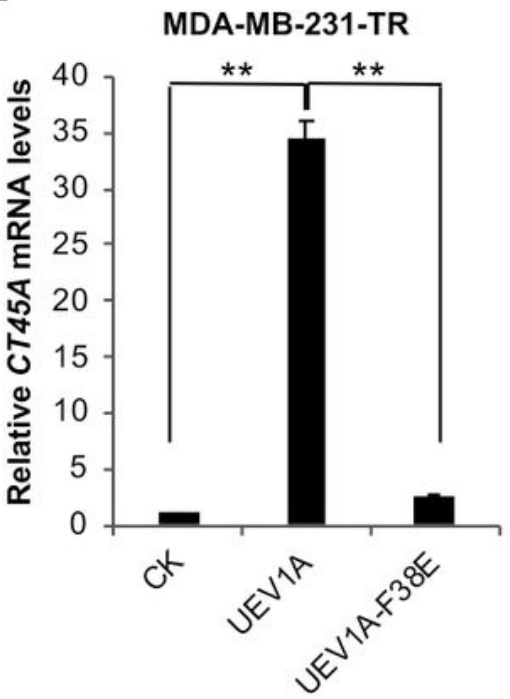

B

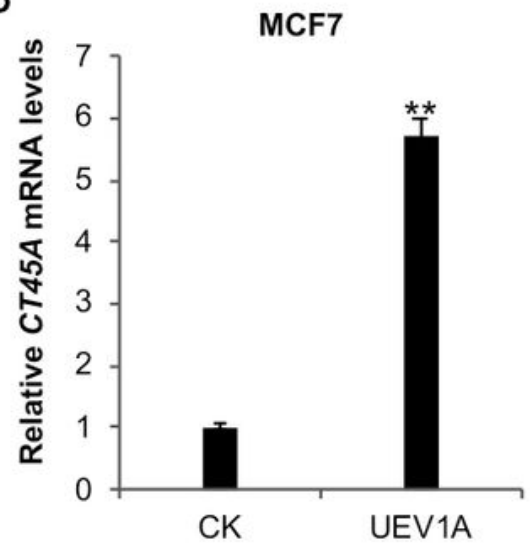

D

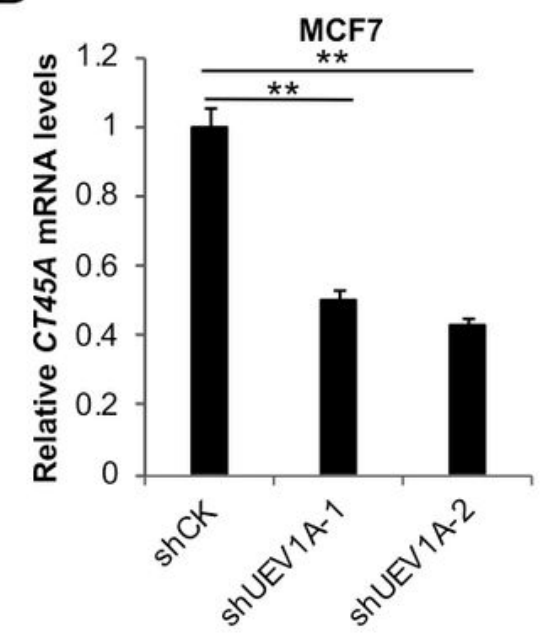

$\mathrm{F}$

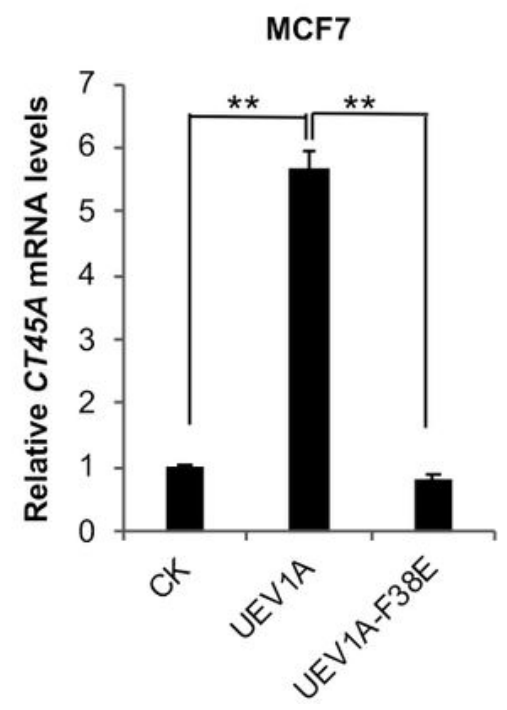

\section{Figure 1}

Uev1A upregulates CT45A expression in a Ubc13-dependent manner in breast cancer cells. (A, B) Relative CT45A transcript levels in UEV1A-overexpressed MDA-MB-231-TR (A) and MCF7 (B) cell lines were monitored by qRT-PCR. CK, control treatment. (C, D) MDA-MB-231 (C) and MCF7 (D) cells were transfected with shRNA lentiviral particles against UEV1A (shUEV1A) or non-specific target (shCK). shUEV1A-1 and shUEV1A-2 represent two independent stable shUEV1A cell lines. CT45A transcript levels 
in shCK and shUEV1A cell lines were monitored by qRT-PCR. (E, F) Overexpressed UEV1A but not UEV1AF38E upregulated CT45A expression in MDA-MB-231 (E) and MCF7 (F) cells, as determined by qRT-PCR. All experiments were performed in at least triplicate and the results are the average with standard deviation. **, $\mathrm{P}<0.01$.
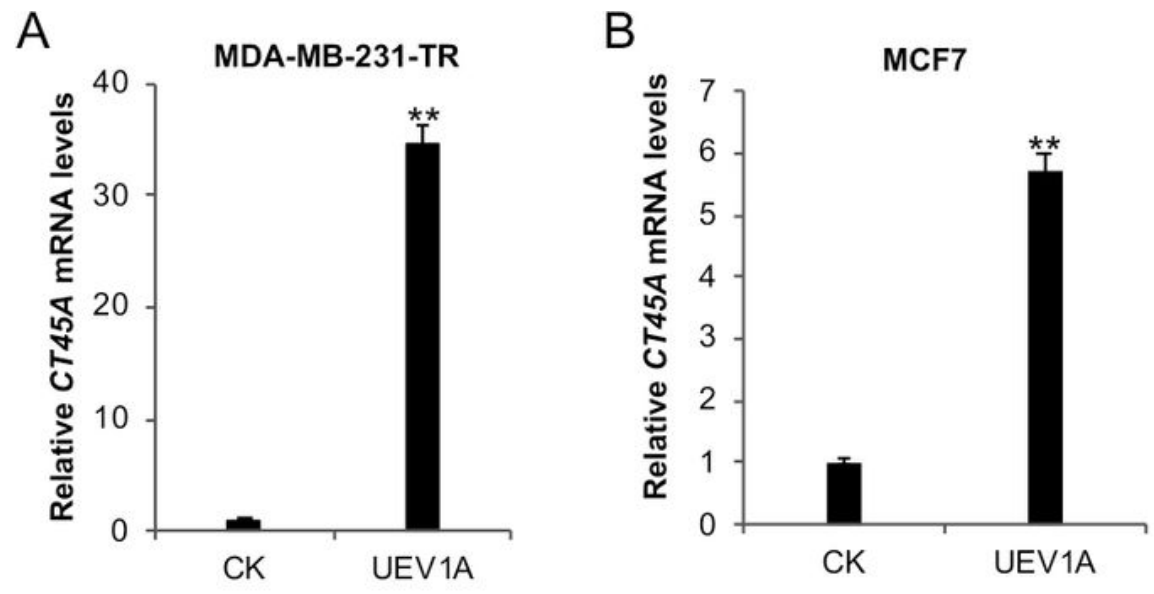

C

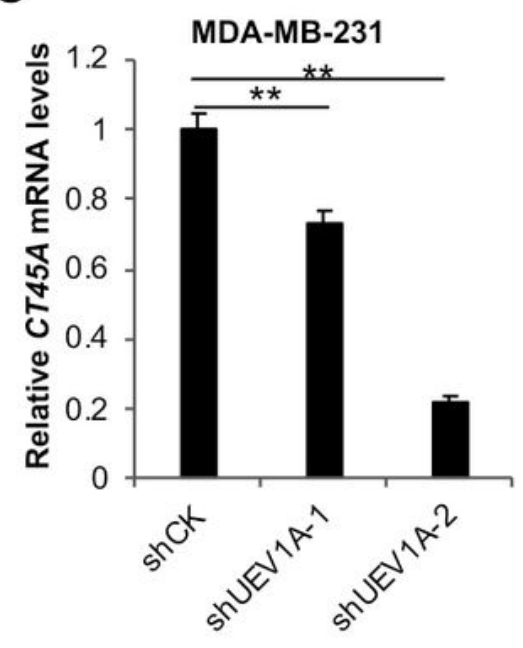

$E$

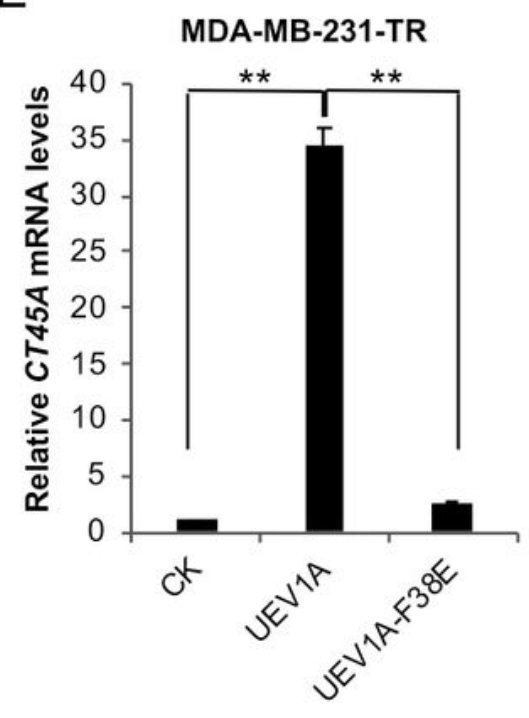

D

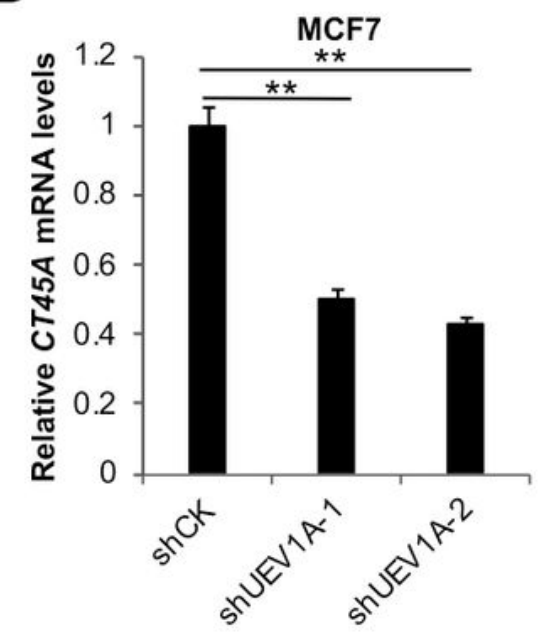

$\mathrm{F}$

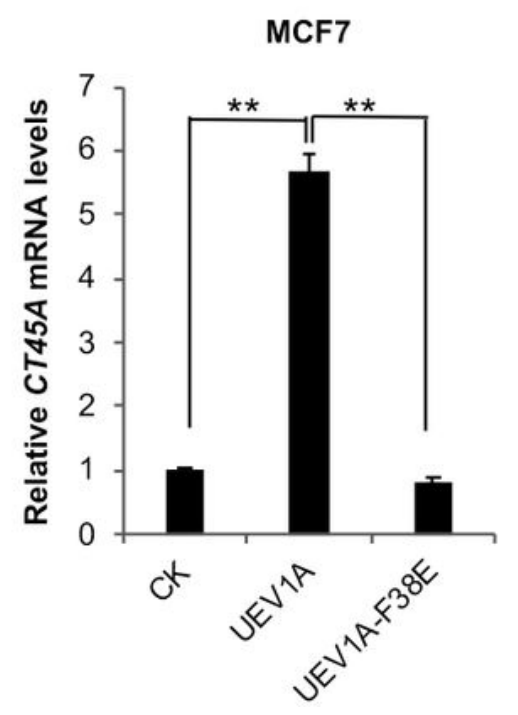

Figure 1 
Uev1A upregulates CT45A expression in a Ubc13-dependent manner in breast cancer cells. (A, B) Relative CT45A transcript levels in UEV1A-overexpressed MDA-MB-231-TR (A) and MCF7 (B) cell lines were monitored by qRT-PCR. CK, control treatment. (C, D) MDA-MB-231 (C) and MCF7 (D) cells were transfected with shRNA lentiviral particles against UEV1A (shUEV1A) or non-specific target (shCK). shUEV1A-1 and shUEV1A-2 represent two independent stable shUEV1A cell lines. CT45A transcript levels in shCK and shUEV1A cell lines were monitored by qRT-PCR. (E, F) Overexpressed UEV1A but not UEV1AF38E upregulated CT45A expression in MDA-MB-231 (E) and MCF7 (F) cells, as determined by qRT-PCR. All experiments were performed in at least triplicate and the results are the average with standard deviation. **, $\mathrm{P}<0.01$. 
A

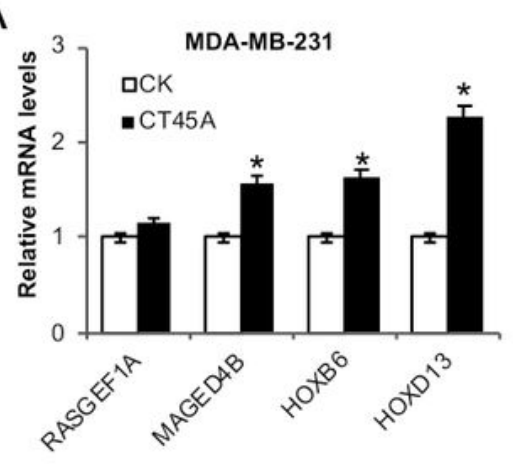

C

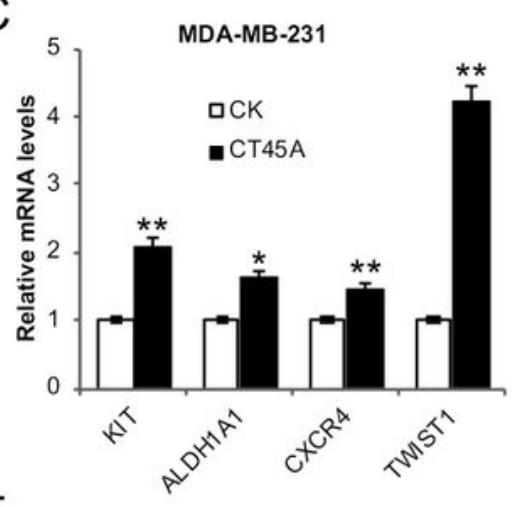

E

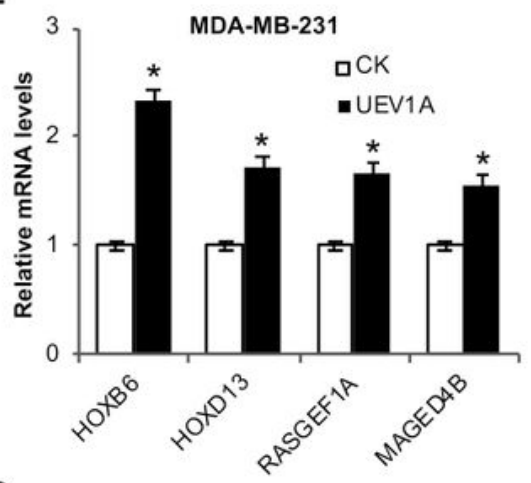

G

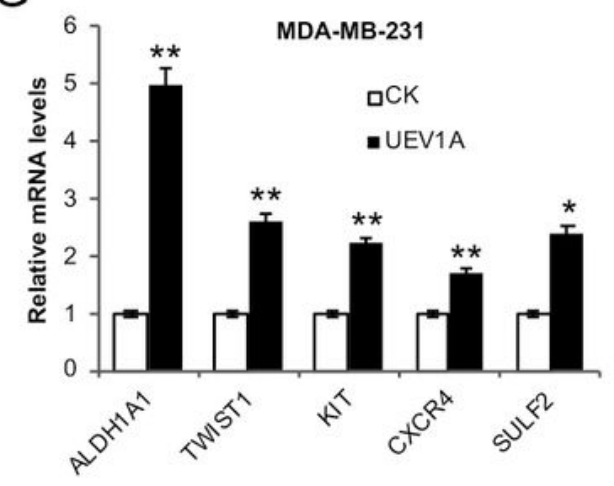

B

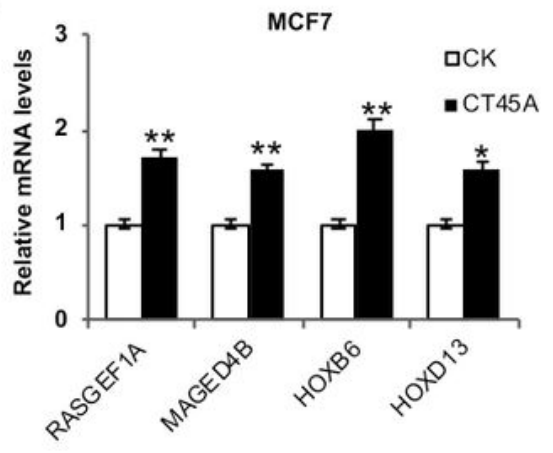

D

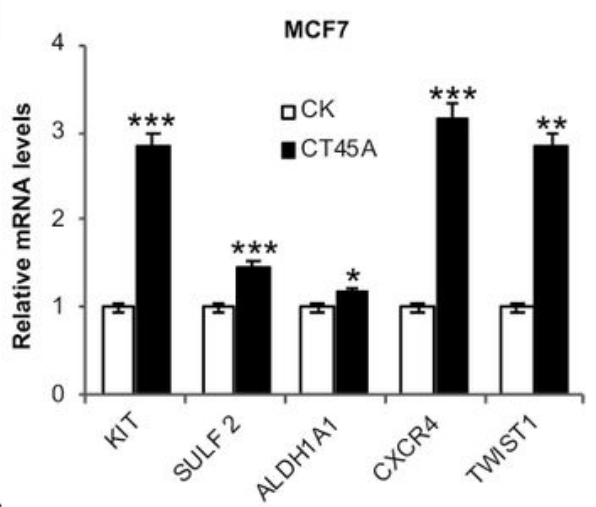

F

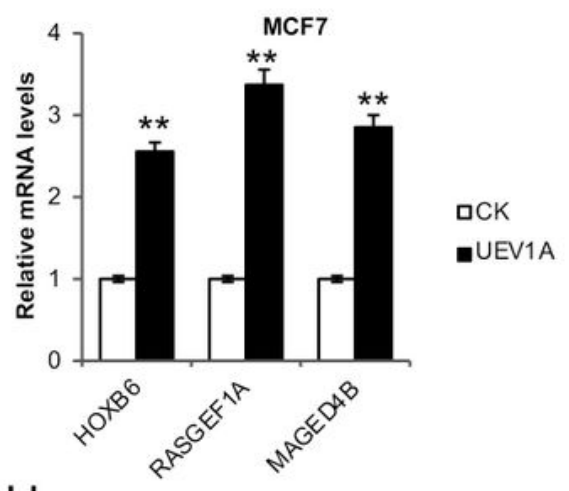

$\mathrm{H}$

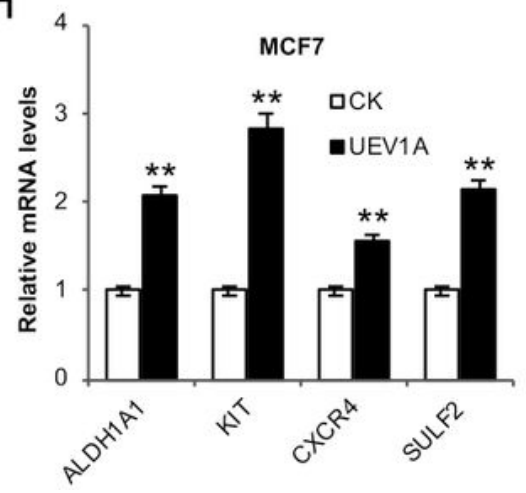

Figure 2

Uev1A positively regulates expression of CT45A downstream genes in breast cancer cells. (A, B) The transcript levels of tumorigenic genes, including RASGEF1A, MAGED4B, HOXB6 and HOXD13 in CT45Aoverexpressed MDA-MB-231 (A) and MCF7 (B) cells were detected by qRT-PCR. (C, D) The transcript levels of EMT, stemness and metastatic genes, including KIT, ALDH1A1, CXCR4, TWIST1 and/or SULF2 in CT45A-overexpressed MDA-MB-231 (C) and MCF7 (D) cells were detected by qRT-PCR. (E, F) The 

HOXD13 in UEV1A transiently overexpressed MDA-MB-231 (E) and MCF7 (F) cells was monitored by qRTPCR. $(G, H)$ The expression of CT45A downsream EMT, stemness and metastasic genes, including ALDH1A1, KIT, CXCR4, SULF2 and/or TWIST1 was monitored in UEV1A transiently overexpressed MDAMB-231 (G) and MCF7 ( $\mathrm{H}$ ) cells by qRT-PCR. All experiments were performed in at least triplicate and the results are the average with standard deviation. *, $\mathrm{P}<0.05 ; * \star, \mathrm{P}<0.01$; and $* * *, \mathrm{P}<0.001$.

A

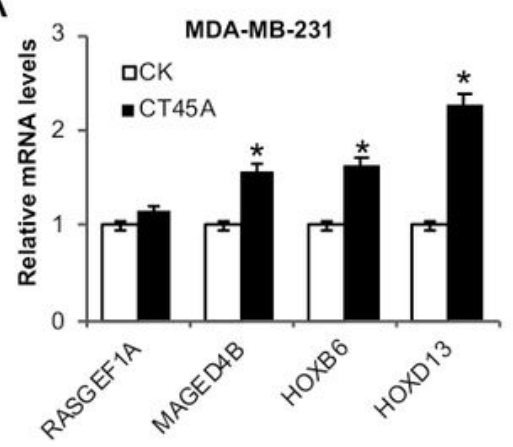

C

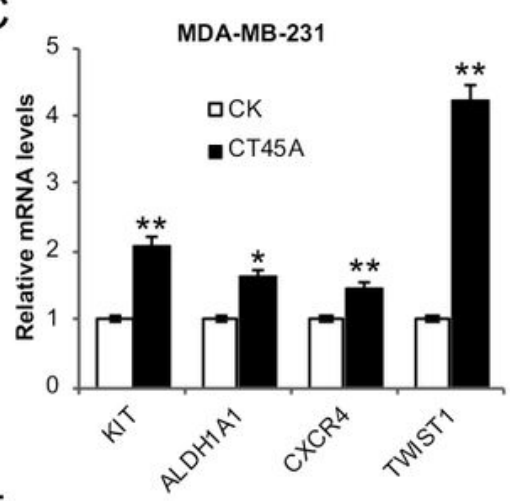

E

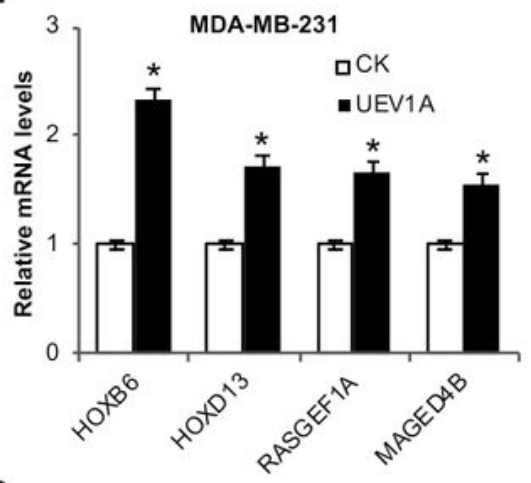

G

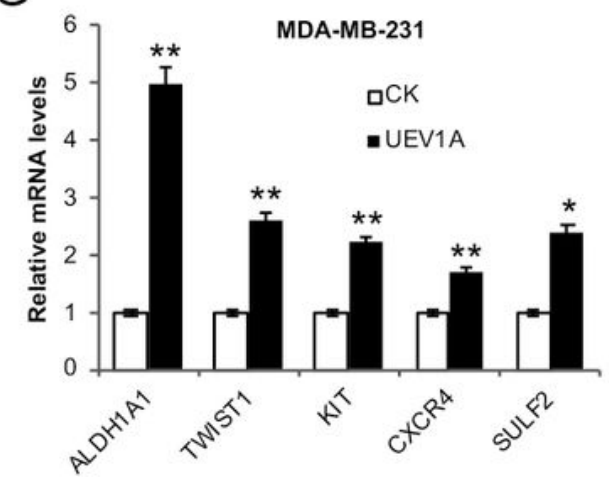

B
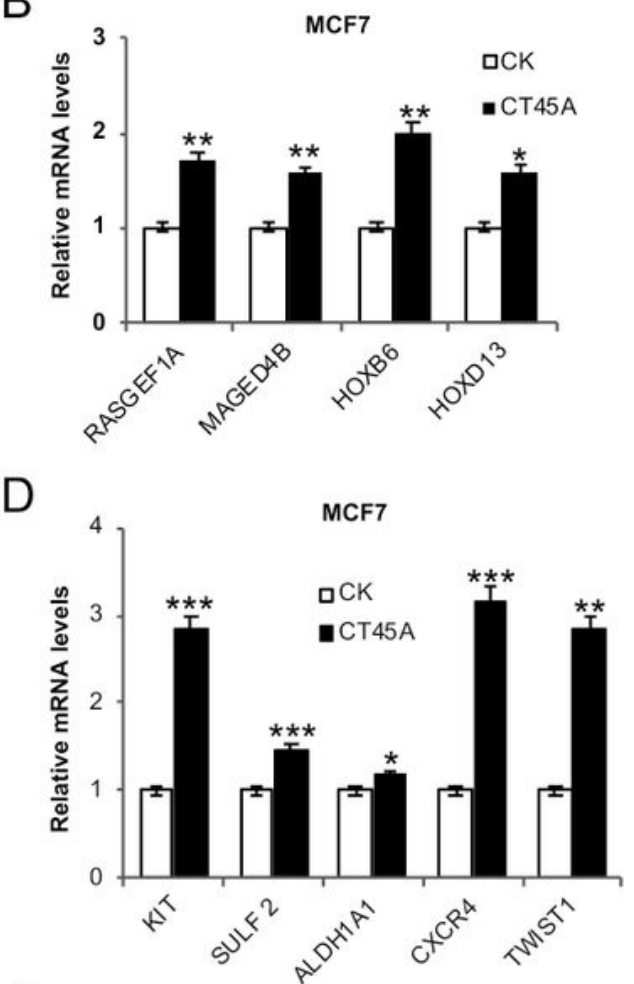

F

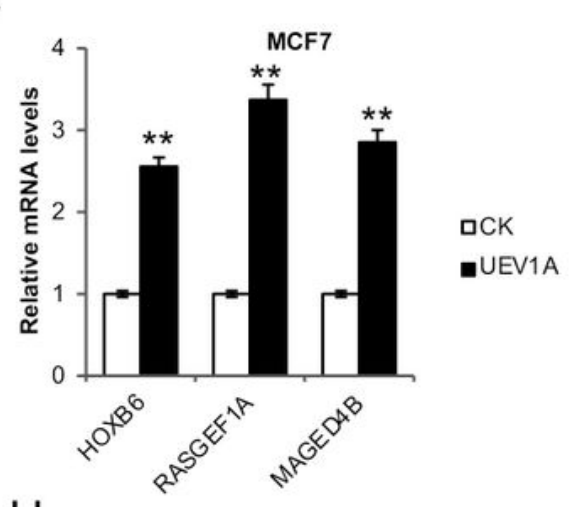

$\mathrm{H}$

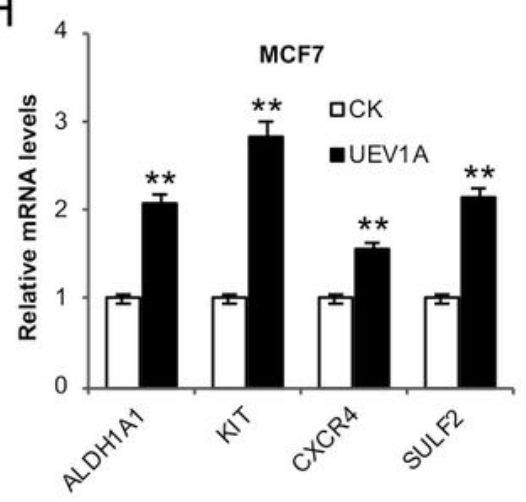

Figure 2 
Uev1A positively regulates expression of CT45A downstream genes in breast cancer cells. (A, B) The transcript levels of tumorigenic genes, including RASGEF1A, MAGED4B, HOXB6 and HOXD13 in CT45Aoverexpressed MDA-MB-231 (A) and MCF7 (B) cells were detected by qRT-PCR. (C, D) The transcript levels of EMT, stemness and metastatic genes, including KIT, ALDH1A1, CXCR4, TWIST1 and/or SULF2 in CT45A-overexpressed MDA-MB-231 (C) and MCF7 (D) cells were detected by qRT-PCR. (E, F) The expression of CT45A downstream tumorigenic genes, including HOXB6, RASGEF1A, MAGED4B and/or HOXD13 in UEV1A transiently overexpressed MDA-MB-231 (E) and MCF7 (F) cells was monitored by qRTPCR. (G, H) The expression of CT45A downsream EMT, stemness and metastasic genes, including ALDH1A1, KIT, CXCR4, SULF2 and/or TWIST1 was monitored in UEV1A transiently overexpressed MDAMB-231 (G) and MCF7 $(\mathrm{H})$ cells by qRT-PCR. All experiments were performed in at least triplicate and the results are the average with standard deviation. * ${ }^{*}<0.05$; $* *, P<0.01$; and $* \star *, P<0.001$. 
A

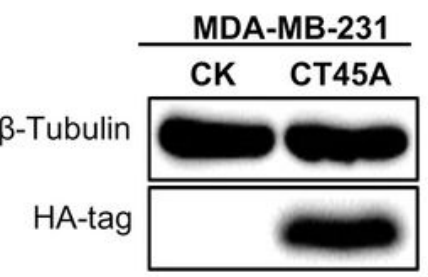

B

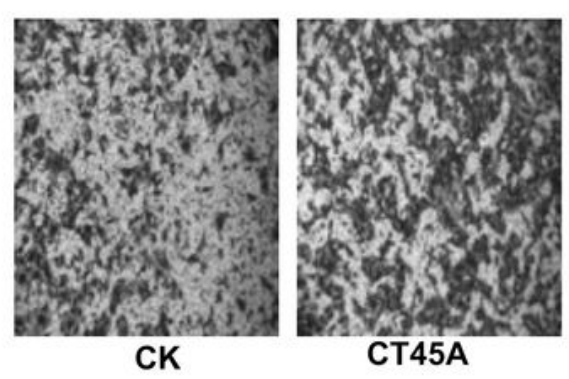

$\mathrm{E}$

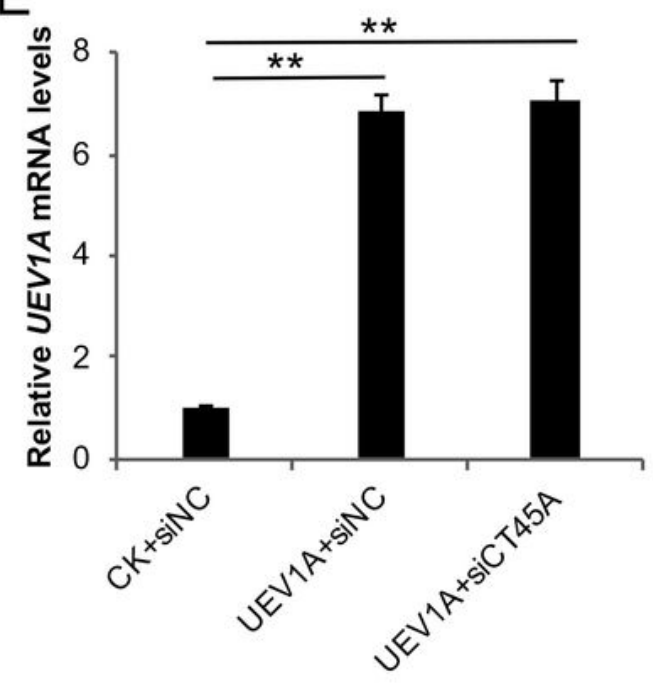

$\mathrm{F}$

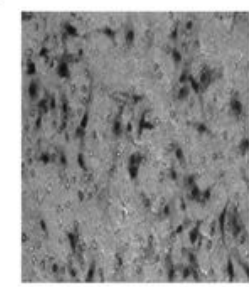

CK+siNC

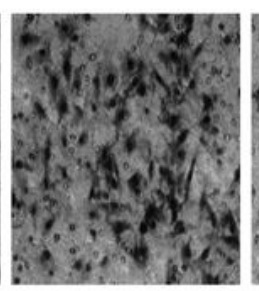

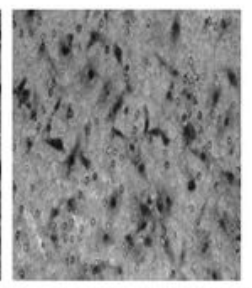

UEV1A+siNC UEV1A+siCT45A
C

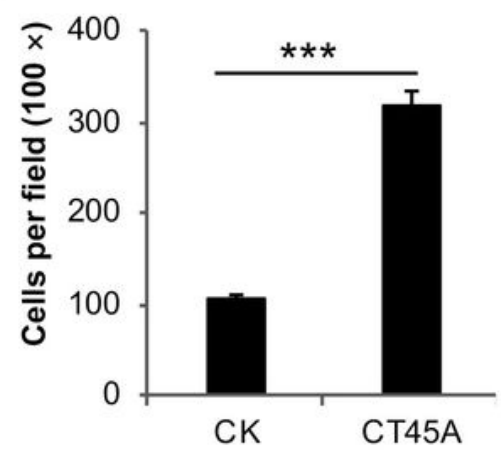

$\mathrm{D}$

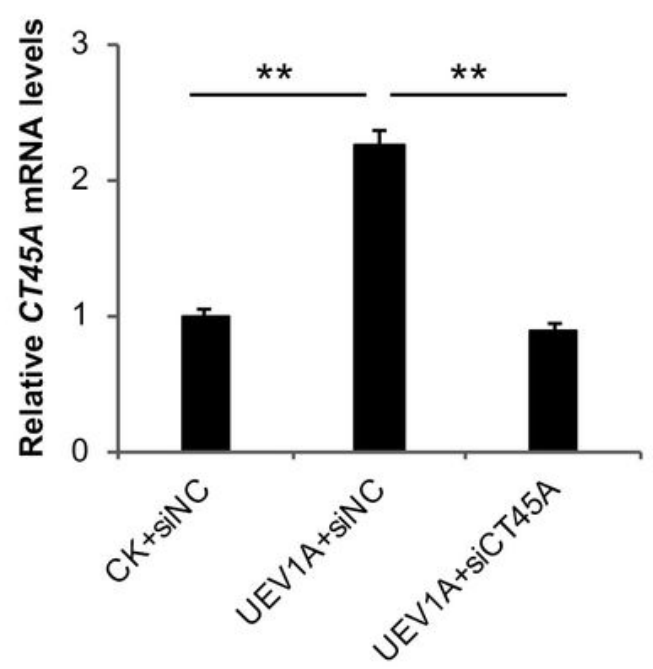

G

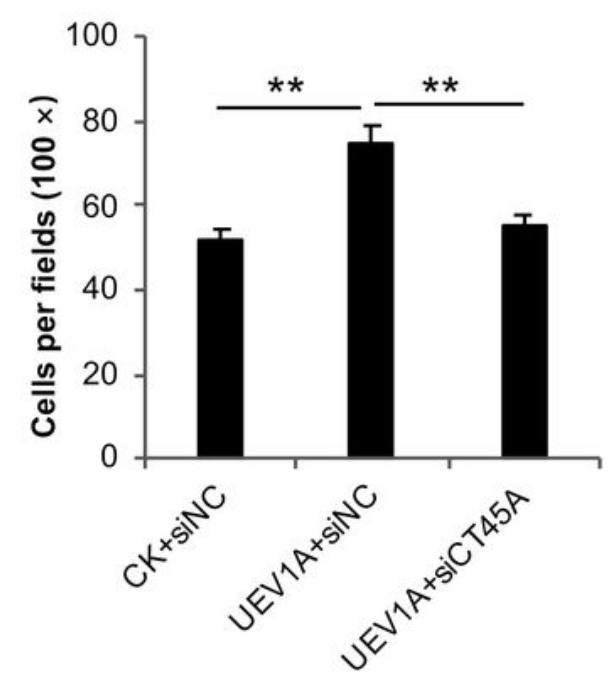

Figure 3

Effcts of manipulation of UEV1A and CT45A expression on MDA-MB-231 cell migration. (A) The ectopic CT45A expression was monitored by western blot against an HA-tag antibody. (B) Representative images of cell migration assay without Matrigel-coated transwell. (C) Statistical analysis of the cell migration assay data. Cells migrated to the lower surface of the filter were counted in five random fields under a light-microscope at $100 \times$ magnification. (D, E) The relative expression of CT45A (D) and UEV1A (E) in 
CT45A-depleted UEV1A transiently-overexpressed cells was monitored by qRT-PCR. (F) Representative images of cell migration ability without Matrigel-coated transwell. MDA-MB-231 cells transiently expressing UEV1A were depleted with CT45A and subjected to the transwell assay. siNC, control siRNA. (G) Statistical analysis of the cell migration assay data. Cells that migrated to the lower surface of the filter were counted in five random fields under a light-microscope at $100 \times$ magnification. All experiments were performed in at least triplicate and the results are the average with standard deviation. ${ }^{\star *}, P<0.01$; and $* * *, P<0.001$.

A

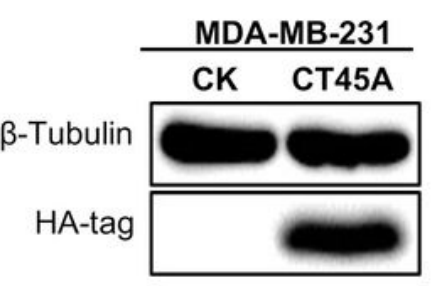

B

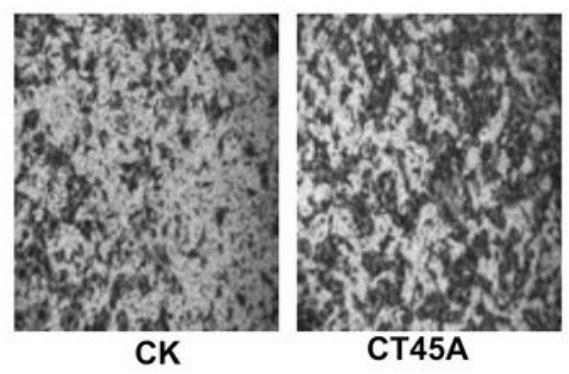

$E$

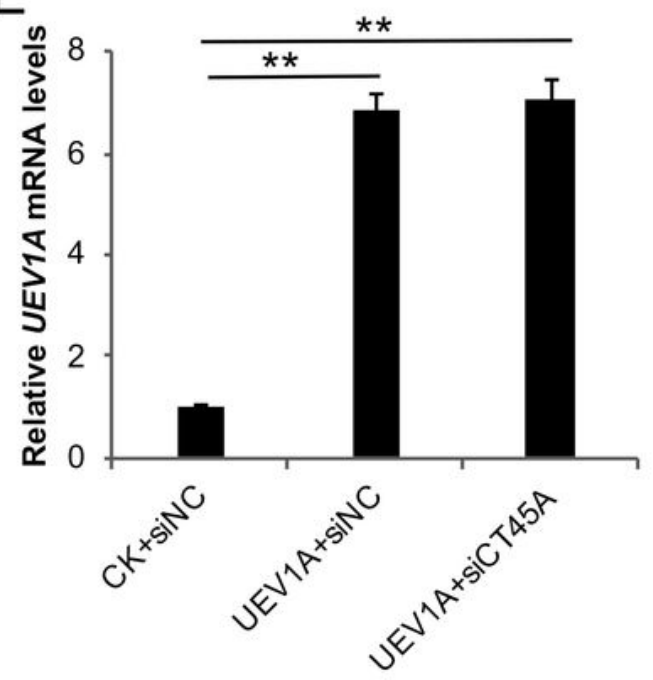

F

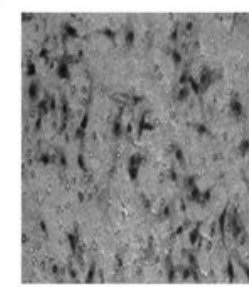

CK+siNC
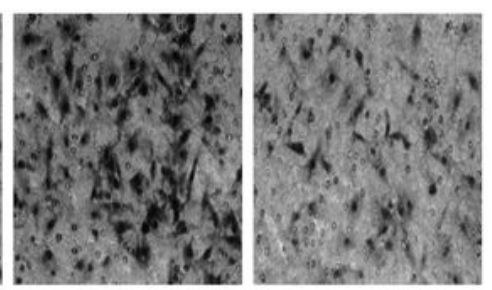

UEV1A+siNC UEV1A+siCT45A
C

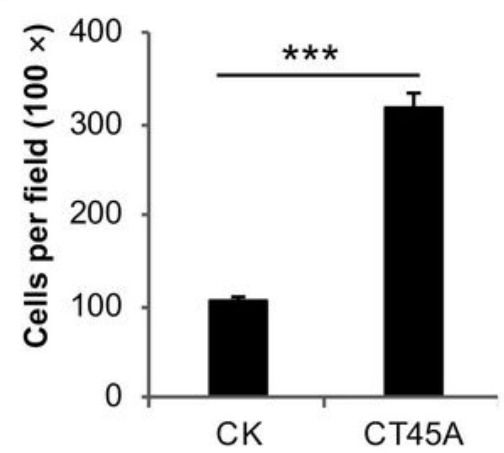

D

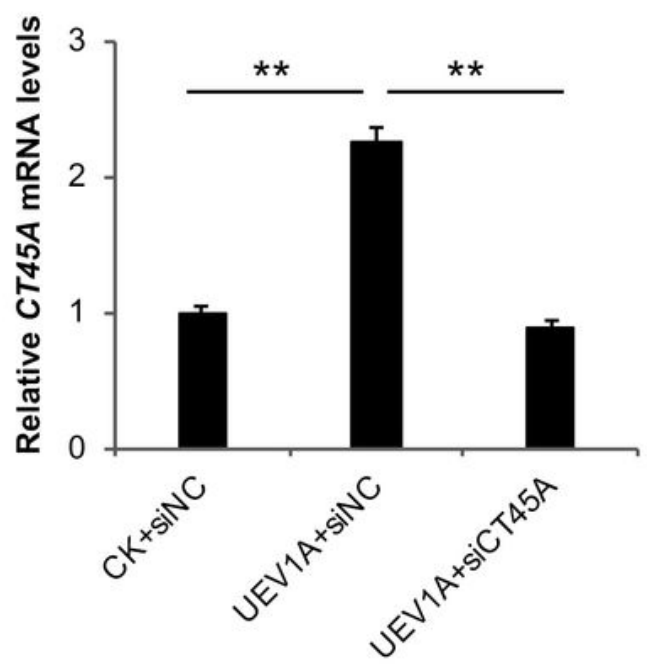

G

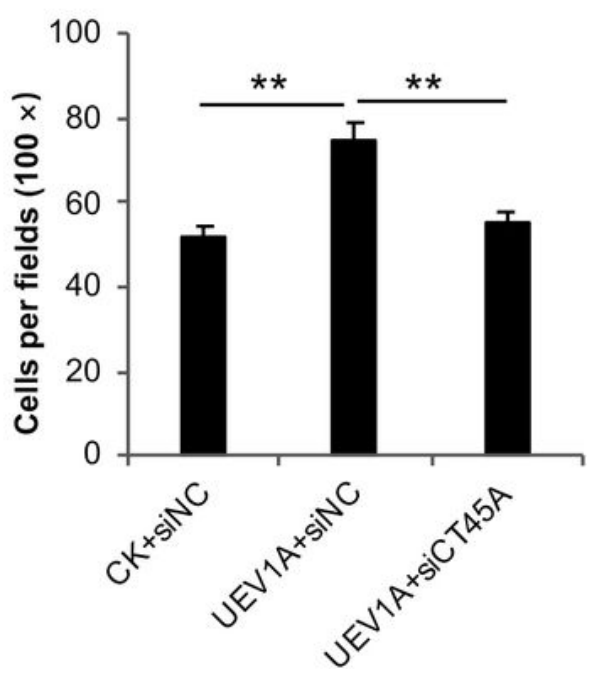




\section{Figure 3}

Effcts of manipulation of UEV1A and CT45A expression on MDA-MB-231 cell migration. (A) The ectopic CT45A expression was monitored by western blot against an HA-tag antibody. (B) Representative images of cell migration assay without Matrigel-coated transwell. (C) Statistical analysis of the cell migration assay data. Cells migrated to the lower surface of the filter were counted in five random fields under a light-microscope at $100 \times$ magnification. (D, E) The relative expression of CT45A (D) and UEV1A (E) in CT45A-depleted UEV1A transiently-overexpressed cells was monitored by qRT-PCR. (F) Representative images of cell migration ability without Matrigel-coated transwell. MDA-MB-231 cells transiently expressing UEV1A were depleted with CT45A and subjected to the transwell assay. siNC, control siRNA. (G) Statistical analysis of the cell migration assay data. Cells that migrated to the lower surface of the filter were counted in five random fields under a light-microscope at $100 \times$ magnification. All experiments were performed in at least triplicate and the results are the average with standard deviation. ${ }^{\star *}, P<0.01$; and $* * *, P<0.001$. 
A

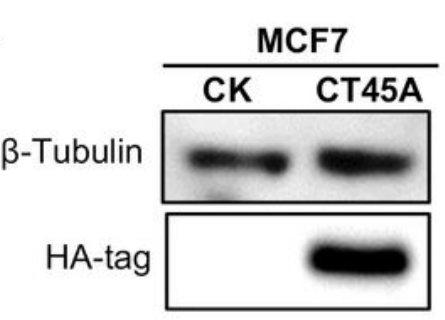

B

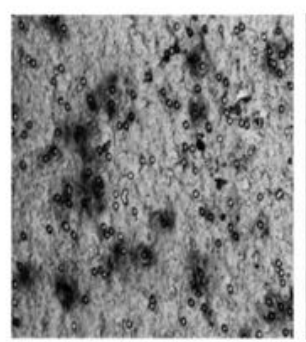

CK

$\mathrm{E}$

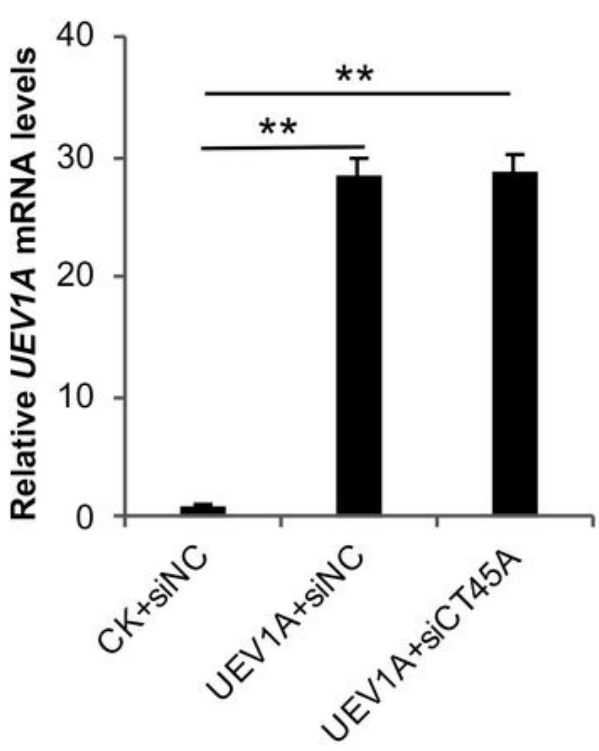

$\mathrm{F}$

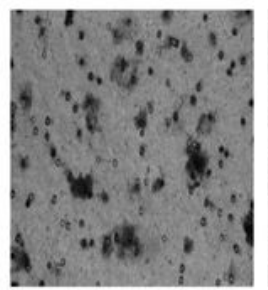

CK+siNC

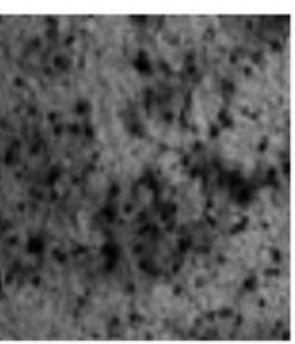

CT45A
D

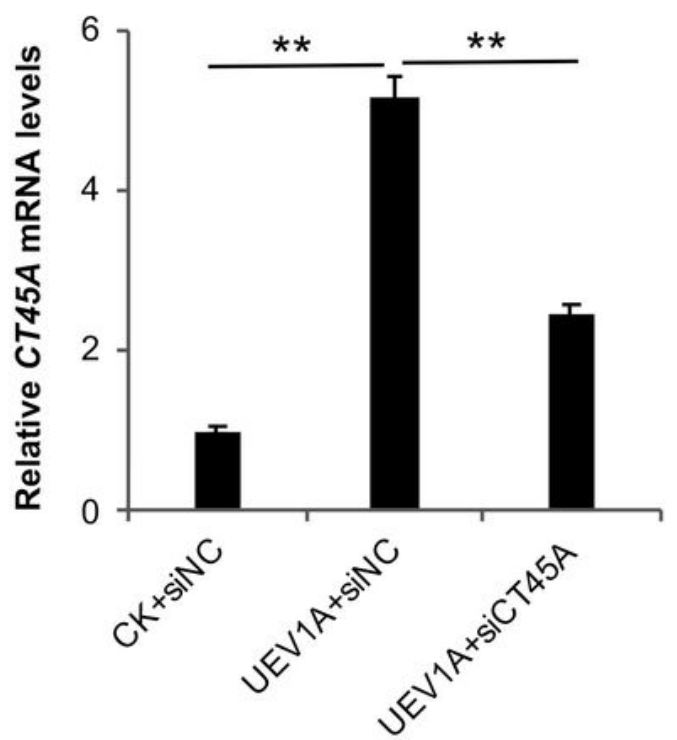

G

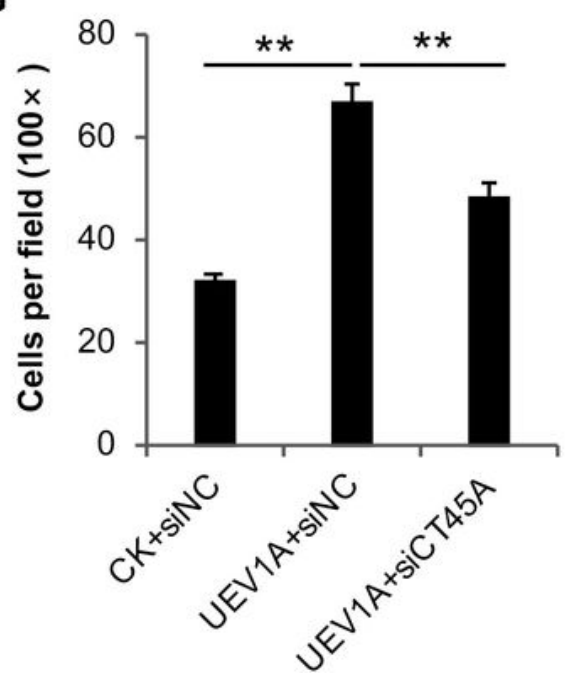

Figure 4

Effcts of manipulation of UEV1A and CT45A expression on MCF7 cell migration. (A) The ectopic CT45A expression was monitored by western blot against an HA-tag antibody. (B) Representative images of cell migration assay without Matrigel-coated transwell. (C) Statistical analysis of the cell migration assay data. (D, E) The relative expression of CT45A (D) and UEV1A (E) in CT45A-depleted UEV1A transientlyoverexpressed cells was monitored by qRT-PCR. (F) Representative images of cell migration ability 
without Matrigel-coated transwell. MCF7 cells transiently expressing UEV1A were depleted with CT45A and subjected to the transwell assay. siNC, control siRNA. (G) Statistical analysis of the cell migration assay data. Cells that migrated to the lower surface of the filter were counted in five random fields under a light-microscope at $100 \times$ magnification. All experiments were performed in at least triplicate and the results are the average with standard deviation. **, $\mathrm{P}<0.01$.

A

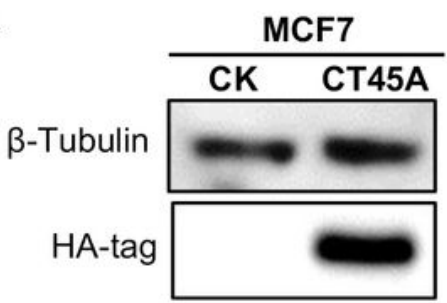

B

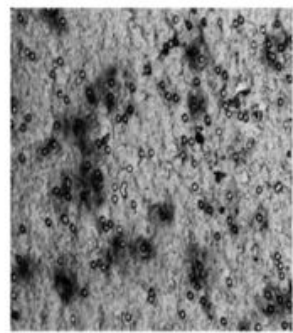

CK

$E$

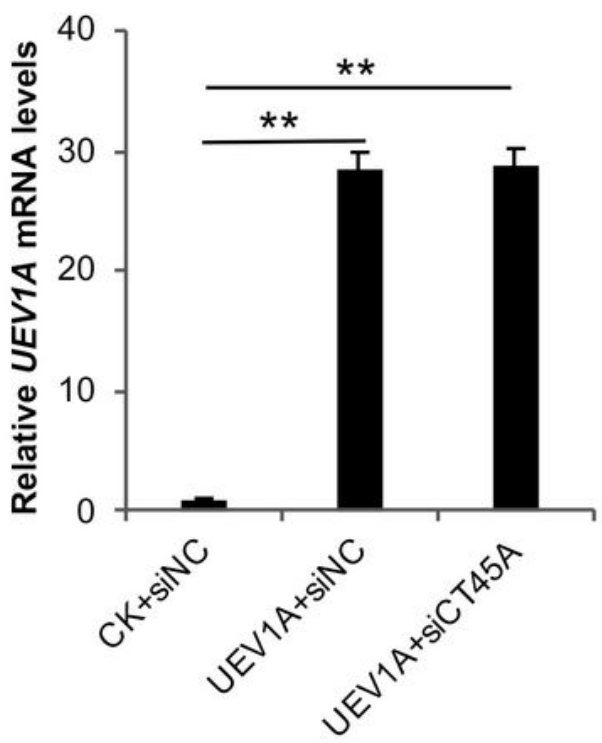

$\mathrm{F}$

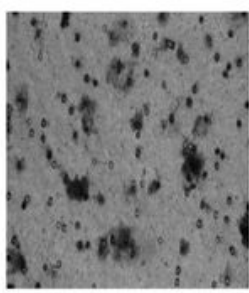

CK+siNC

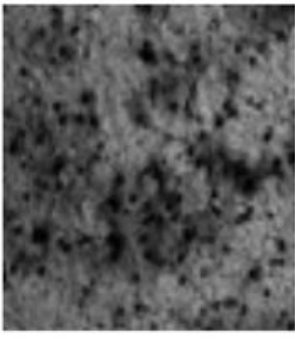

CT45A
D

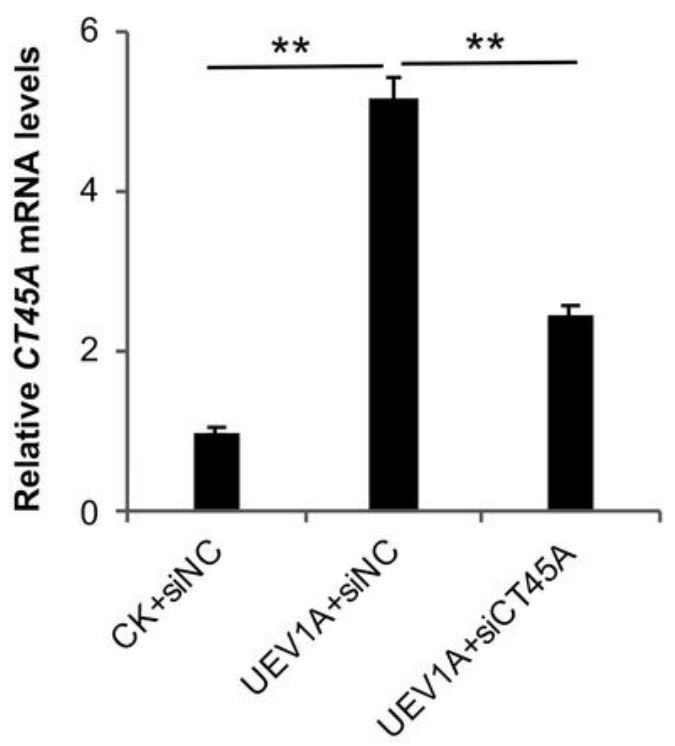

G

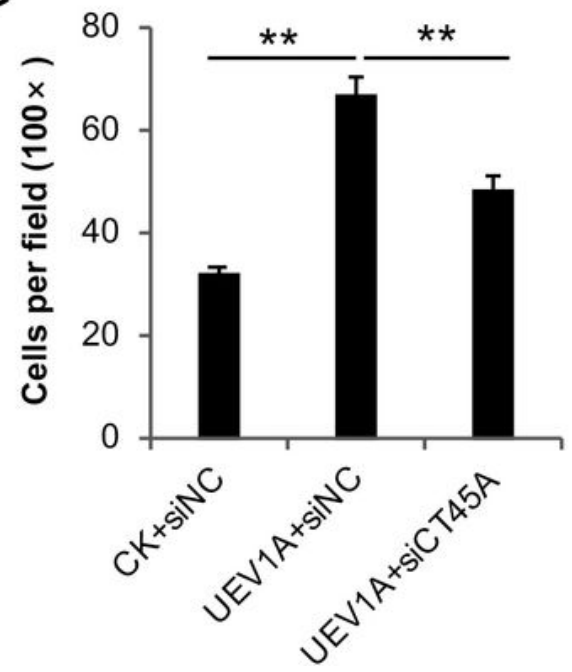

Figure 4

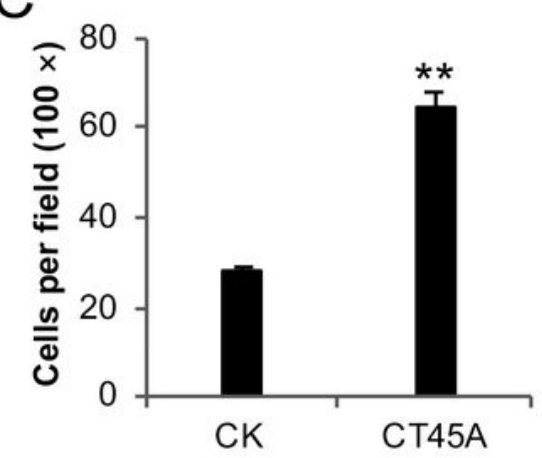


Effcts of manipulation of UEV1A and CT45A expression on MCF7 cell migration. (A) The ectopic CT45A expression was monitored by western blot against an HA-tag antibody. (B) Representative images of cell migration assay without Matrigel-coated transwell. (C) Statistical analysis of the cell migration assay data. (D, E) The relative expression of CT45A (D) and UEV1A (E) in CT45A-depleted UEV1A transientlyoverexpressed cells was monitored by qRT-PCR. (F) Representative images of cell migration ability without Matrigel-coated transwell. MCF7 cells transiently expressing UEV1A were depleted with CT45A and subjected to the transwell assay. siNC, control siRNA. (G) Statistical analysis of the cell migration assay data. Cells that migrated to the lower surface of the filter were counted in five random fields under a light-microscope at $100 \times$ magnification. All experiments were performed in at least triplicate and the results are the average with standard deviation. $* \star, P<0.01$. 
A

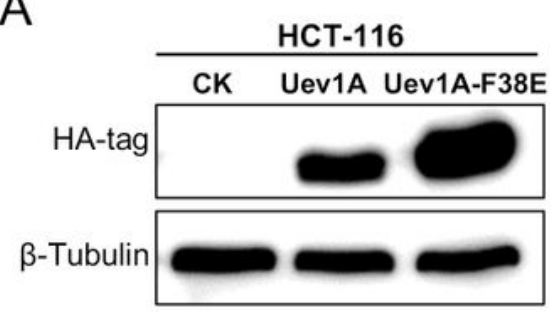

C

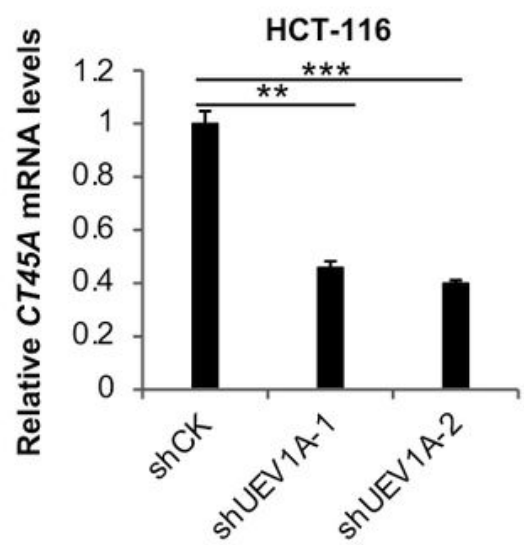

$E$

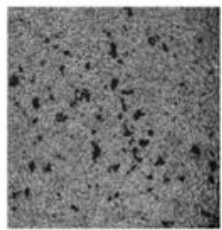

CK

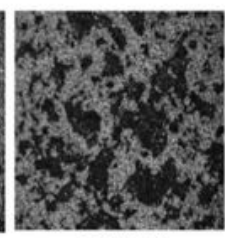

CT45A
B

D
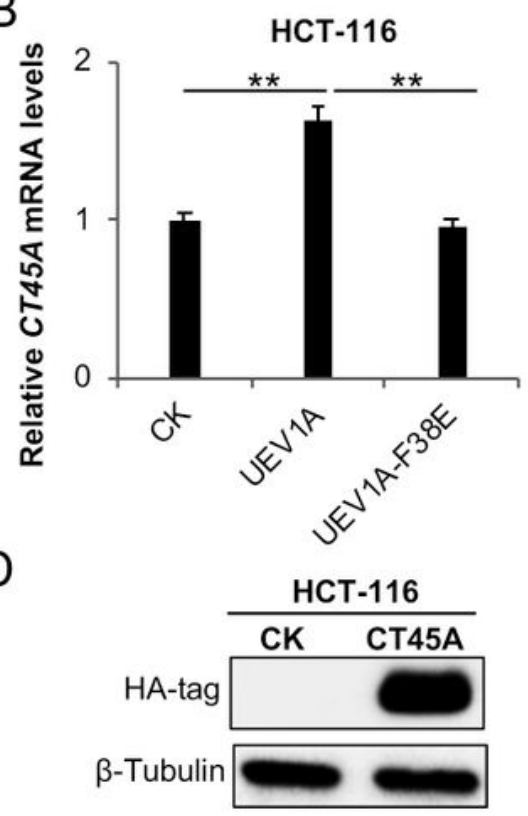

F

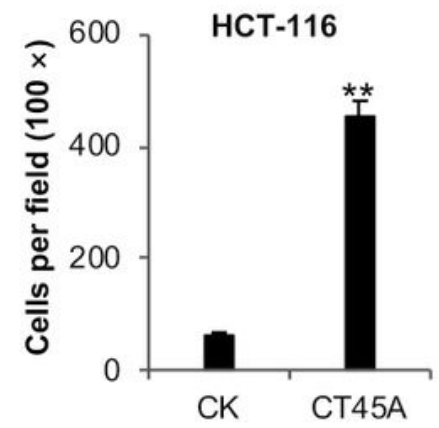

$\mathrm{H}$

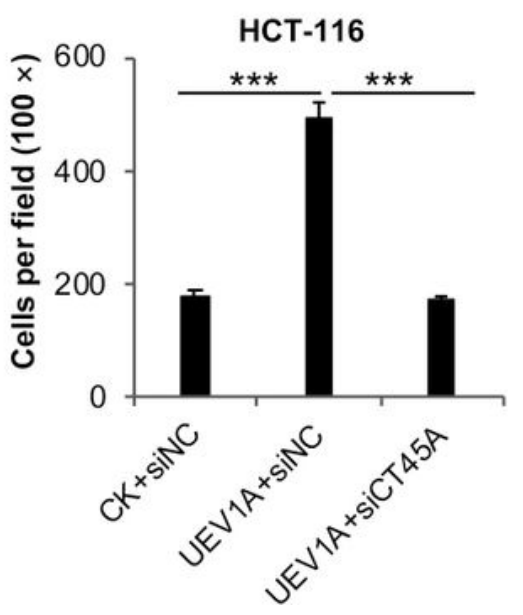

Figure 5

CT45A promotes metastasis in HCT116 colorectal cancer cells. (A) Cellular HA-tagged Uev1A and Uev1AF38E were detected by western blot against HA-tag antibody. (B) Overexpressed UEV1A but not UEV1AF38E upregulated CT45A expression in HCT116 colorectal cells. (C) HCT116 cells were transfected with shRNA lentiviral particles against UEV1A (shUEV1A) or non-specific target (shCK). CT45A transcript levels in shCK and shUEV1A cell lines were monitored by qRT-PCR. (D) Cellular HA-tagged CT45A was detected 
by western blot against HA-tag antibody. (E) Representative images of HCT116 cell migration assay without Matrigel-coated transwell. (F) Statistical analysis of the cell migration assay data. Cells that migrated to the lower surface of the filter were counted in five random fields under a light-microscope at $100 \times$ magnification. (G) Representative images of HCT116 cell migration ability without Matrigel-coated transwell. HCT116 cells expressing UEV1A were depleted with CT45A and subjected to the transwell assay. siNC, control siRNA. (H) Statistical analysis of the cell migration assay data. All experiments were performed in at least triplicate and the results are the average with standard deviation. $* \star, P<0.01$; and $* \star *$, $\mathrm{P}<0.001$. 
A

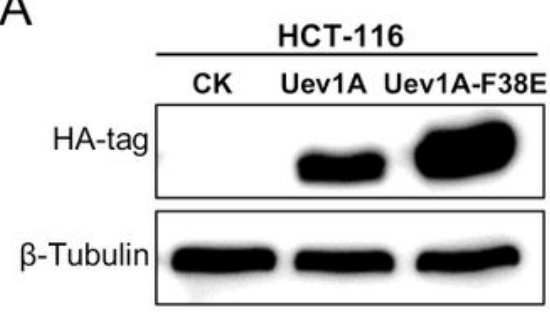

C

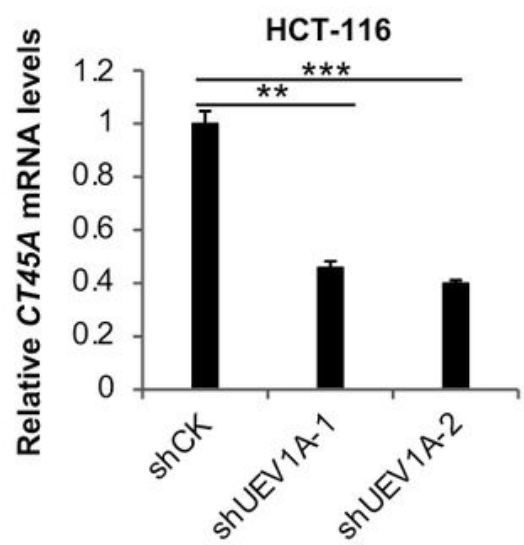

$E$

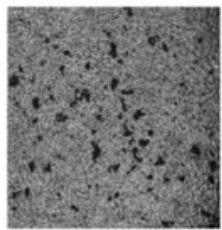

CK

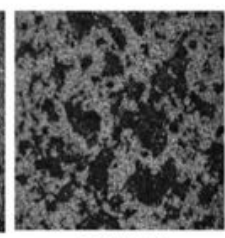

CT45A
B

D
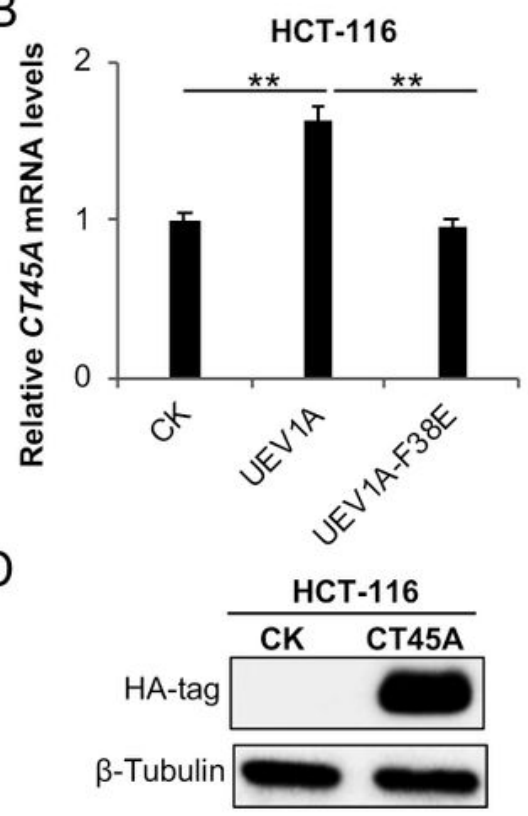

F

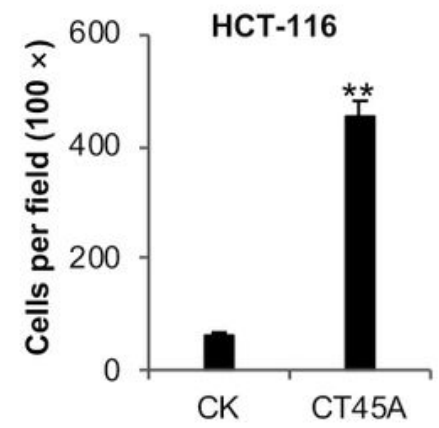

$\mathrm{H}$

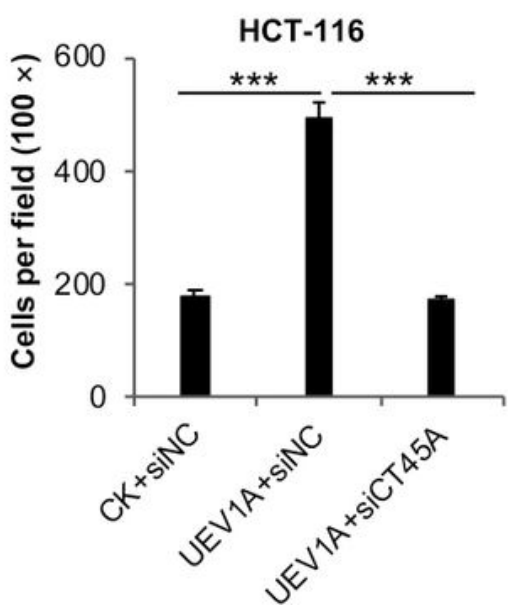

Figure 5

CT45A promotes metastasis in HCT116 colorectal cancer cells. (A) Cellular HA-tagged Uev1A and Uev1AF38E were detected by western blot against HA-tag antibody. (B) Overexpressed UEV1A but not UEV1AF38E upregulated CT45A expression in HCT116 colorectal cells. (C) HCT116 cells were transfected with shRNA lentiviral particles against UEV1A (shUEV1A) or non-specific target (shCK). CT45A transcript levels in shCK and shUEV1A cell lines were monitored by qRT-PCR. (D) Cellular HA-tagged CT45A was detected 
by western blot against HA-tag antibody. (E) Representative images of HCT116 cell migration assay without Matrigel-coated transwell. (F) Statistical analysis of the cell migration assay data. Cells that migrated to the lower surface of the filter were counted in five random fields under a light-microscope at $100 \times$ magnification. (G) Representative images of HCT116 cell migration ability without Matrigel-coated transwell. HCT116 cells expressing UEV1A were depleted with CT45A and subjected to the transwell assay. siNC, control siRNA. (H) Statistical analysis of the cell migration assay data. All experiments were performed in at least triplicate and the results are the average with standard deviation. $* \star, P<0.01$; and $* \star *$, $\mathrm{P}<0.001$. 
A

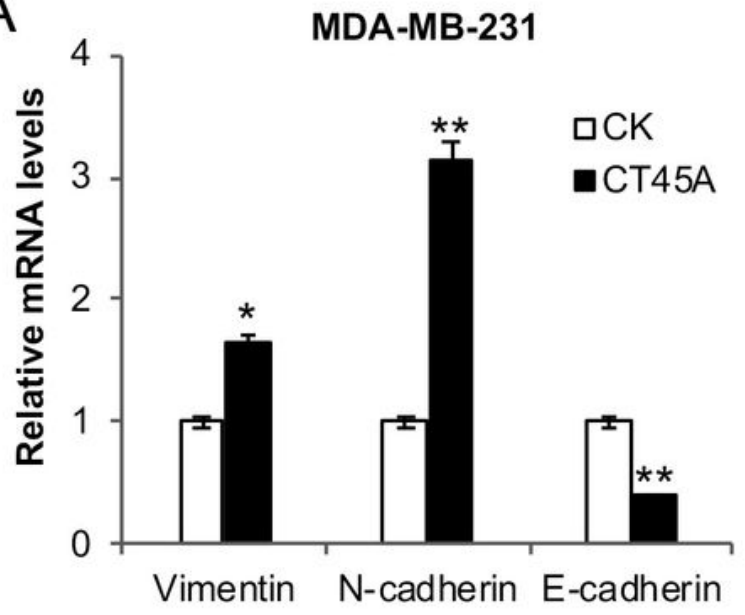

B

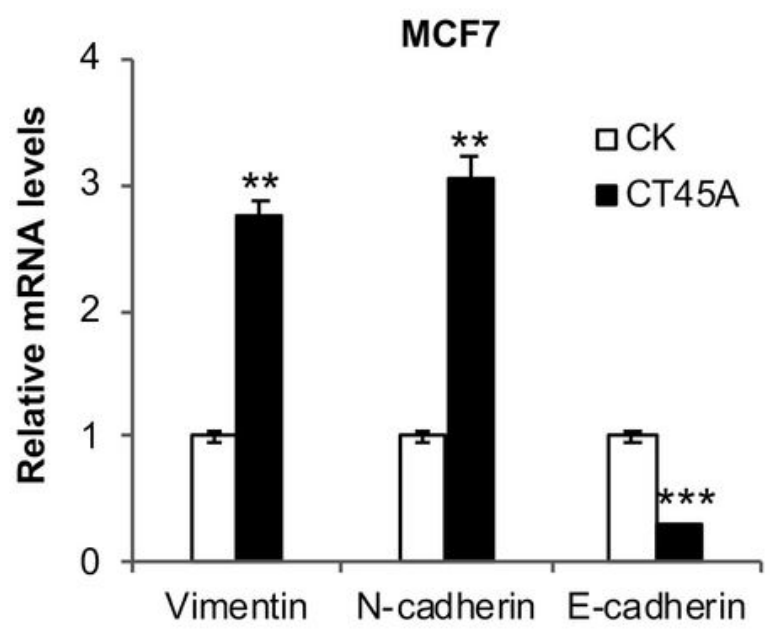

C

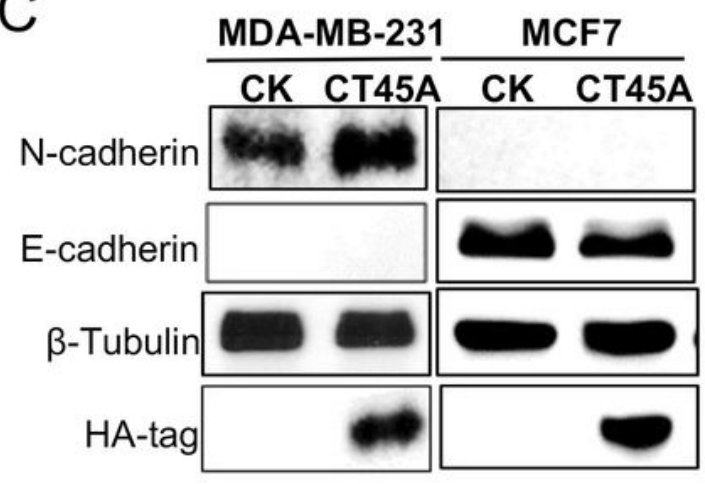

E MDA-MB-231

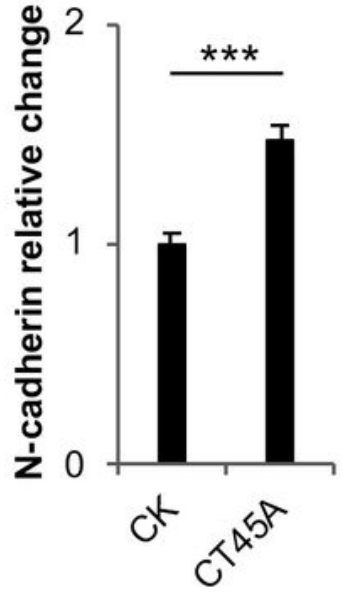

F

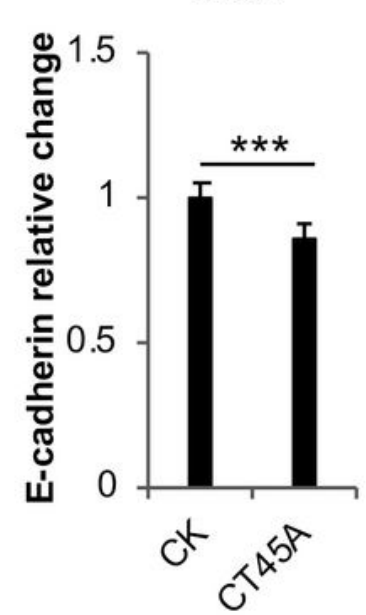

D
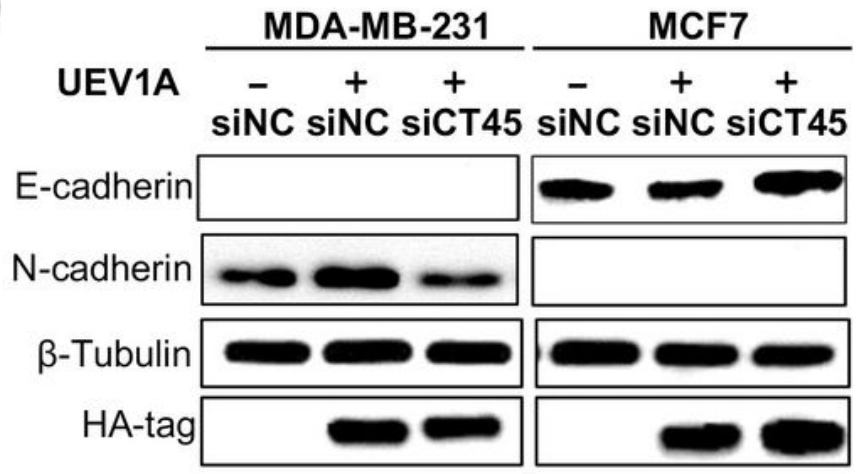

G MDA-MB-231

$\mathrm{H}$

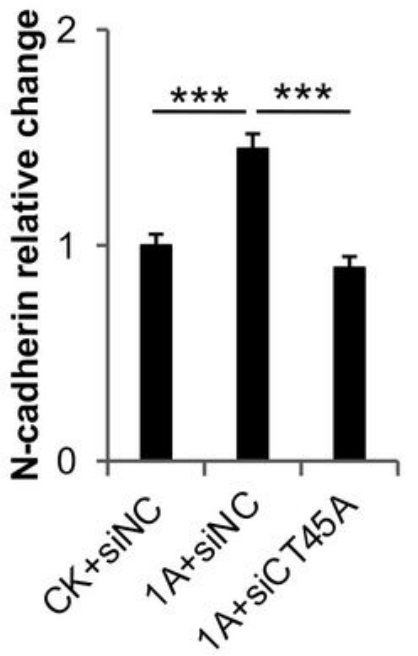

MCF7

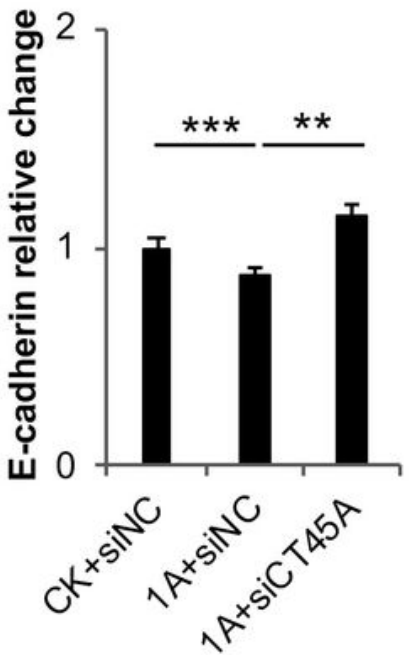

Figure 6

Effects of CT45A and UEV1A expression on EMT in breast cancer cells. (A, B) The relative transcript levels of EMT markers, including epithelial markers E-cadherin and mesenchymal markers $\mathrm{N}$-cadherin, vimentin in CT45A-overexpressed MDA-MB-231 (A) and MCF7 (B) cells were determined by qRT-PCR. (C) The expression of N-cadherin and E-cadherin in CT45A-overexpressed MDA-MB-231 (left panel) and MCF7 (right panel) cells was detected by western blot against anti-N-cadherin and anti-E-cadherin antibodies. 
(D) The expression of N-cadherin and E-cadherin in MDA-MB-231 (left panel) and MCF7 (right panel) cells transiently overexpressing UEV1A and depleted with CT45A was detected by western blot using anti-Ncadherin and anti-E-cadherin antibodies. $(\mathrm{E}-\mathrm{H})$ Statistical analyses of relative cellular N-cadherin and Ecadherin levels in MDA-MB-231 $(\mathrm{E}, \mathrm{G})$ and MCF7 $(\mathrm{F}, \mathrm{H})$ cells as indicated in the graphs. All experiments were performed in at least triplicate and the results are the average with standard deviation. ${ }^{\star *}, P<0.01$; and $* * *, P<0.001$.

A

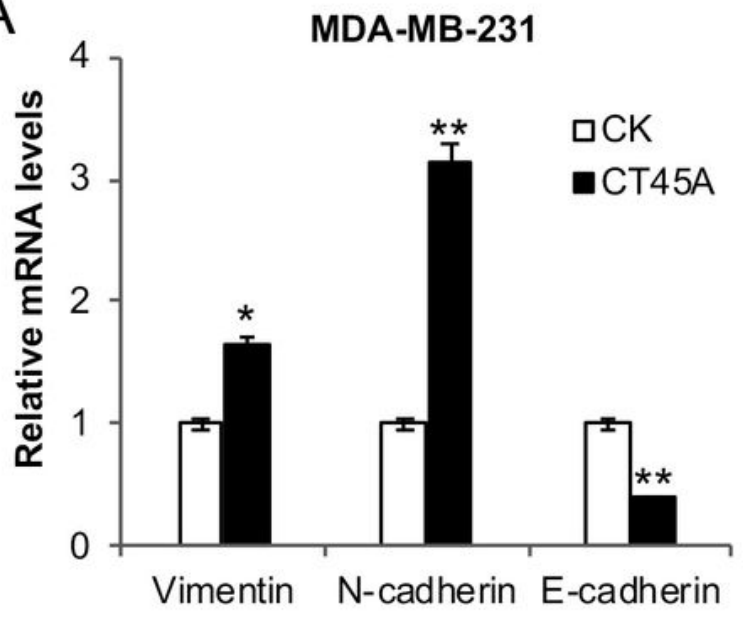

B

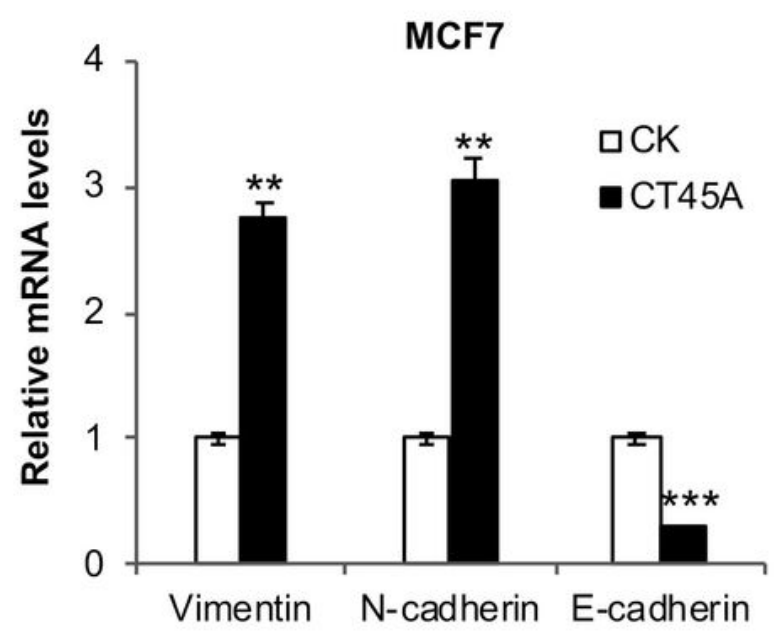

C

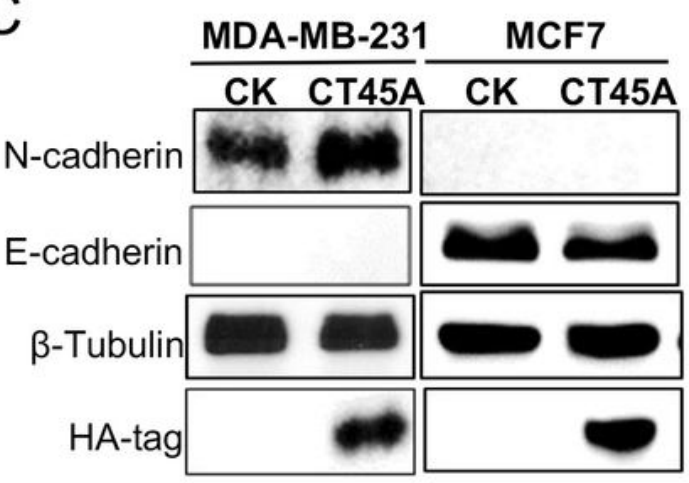

$E$

MDA-MB-231

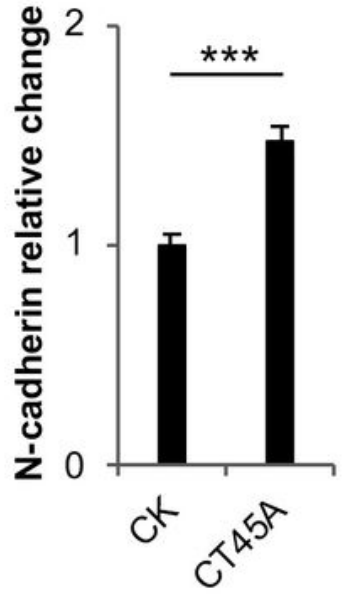

F

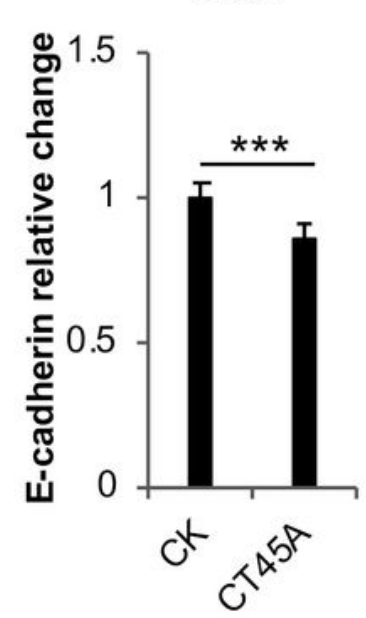

D

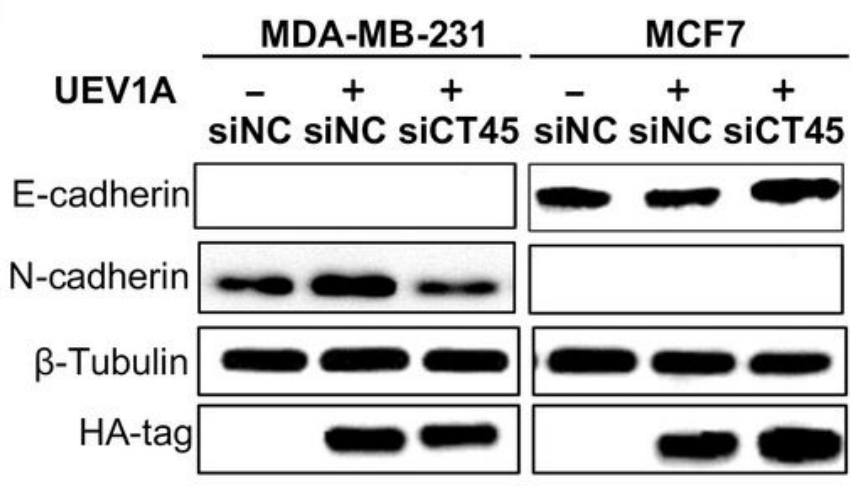

$\mathrm{H}$

MDA-MB-231

MCF7
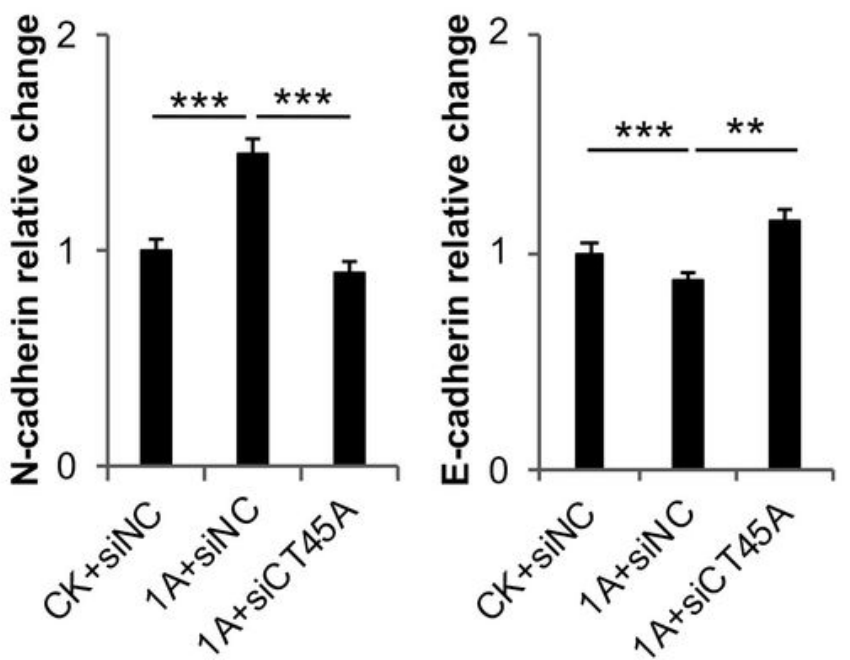

Figure 6 
Effects of CT45A and UEV1A expression on EMT in breast cancer cells. (A, B) The relative transcript levels of EMT markers, including epithelial markers E-cadherin and mesenchymal markers $\mathrm{N}$-cadherin, vimentin in CT45A-overexpressed MDA-MB-231 (A) and MCF7 (B) cells were determined by qRT-PCR. (C) The expression of N-cadherin and E-cadherin in CT45A-overexpressed MDA-MB-231 (left panel) and MCF7 (right panel) cells was detected by western blot against anti-N-cadherin and anti-E-cadherin antibodies.

(D) The expression of N-cadherin and E-cadherin in MDA-MB-231 (left panel) and MCF7 (right panel) cells transiently overexpressing UEV1A and depleted with CT45A was detected by western blot using anti-Ncadherin and anti-E-cadherin antibodies. (E-H) Statistical analyses of relative cellular N-cadherin and Ecadherin levels in MDA-MB-231 $(E, G)$ and MCF7 $(F, H)$ cells as indicated in the graphs. All experiments were performed in at least triplicate and the results are the average with standard deviation. ${ }^{\star *}, P<0.01$; and $* \star \star, ~ P<0.001$. 
A

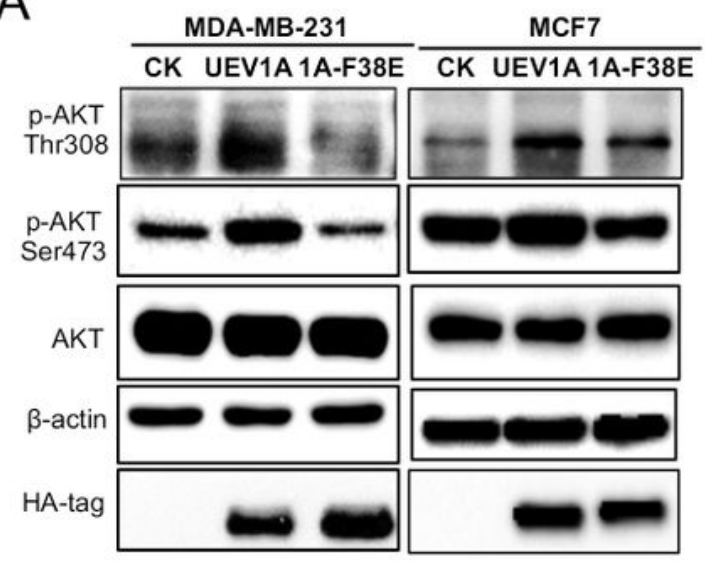

C

MDA-MB-231

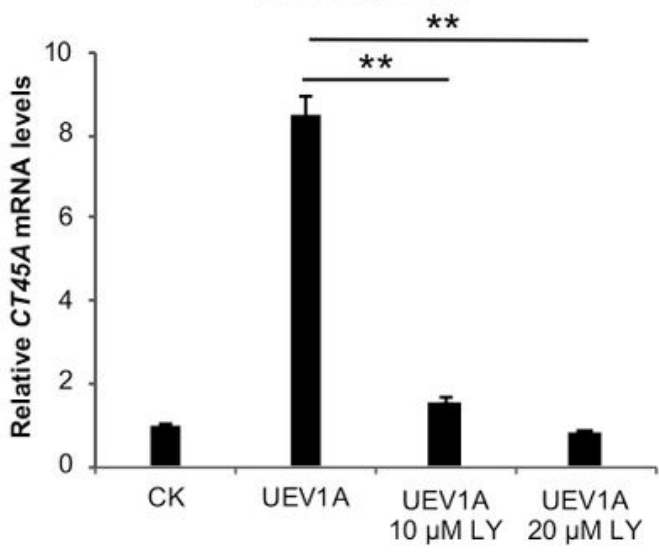

E

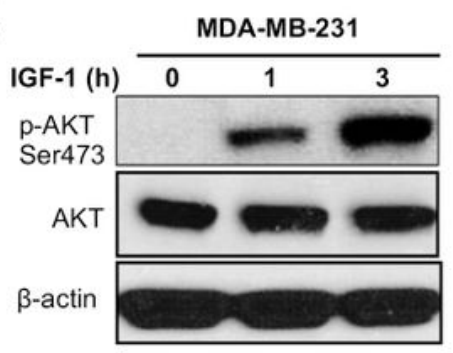

$\mathrm{F}$

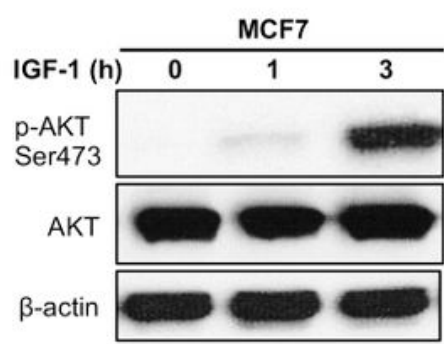

B

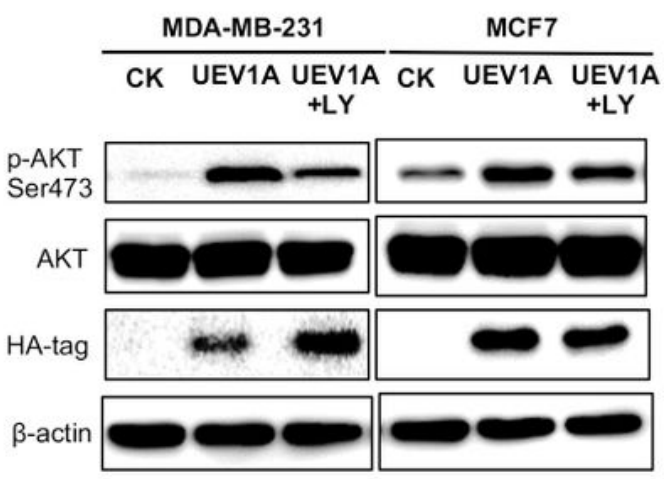

D

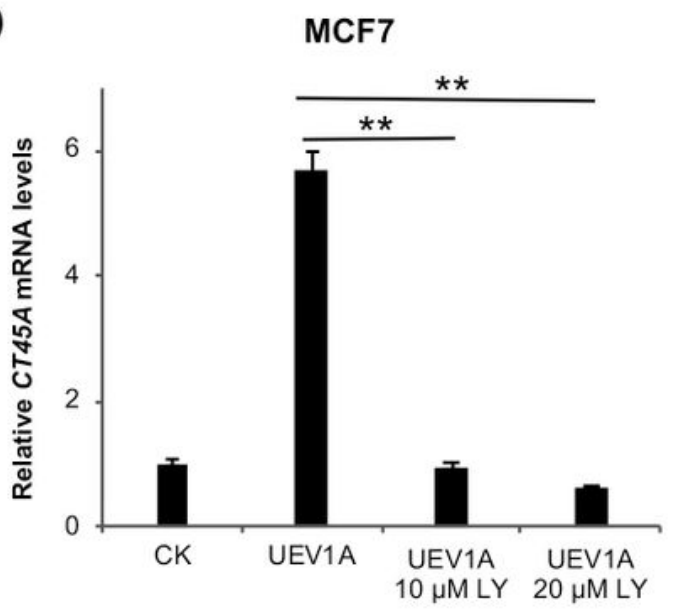

$\mathrm{H}$

MDA-MB-231
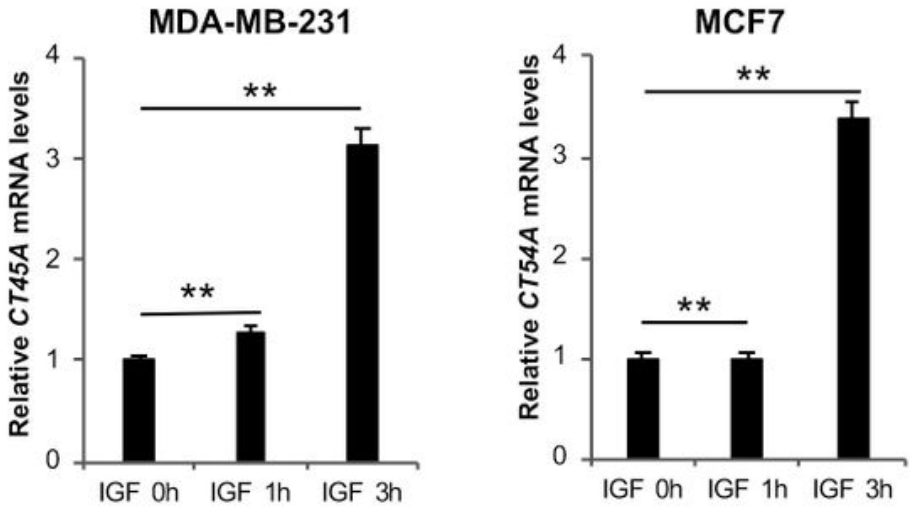

\section{Figure 7}

Uev1 A regulates CT45A expression through the AKT signaling pathway. (A) The cellular AKT protein and its phosphorylation (p-AKT-Thr308, p-AKT-Ser473) levels in pcDNA4.0/TO/HA (+) vector (CK), UEV1A, UEV1A-F38E transiently-transfected MDA-MB-231 (left panel) and MCF7 (right panel) cells were monitored by western blot using anti-AKT, anti-p-AKT-Thr308 and anti-p-AKT-Ser473 antibodies. (B) The UEV1A transiently-transfected MDA-MB-231 (left panel) and MCF7 (right panel) cells were treated with 10 
$\mu \mathrm{M}$ PI3K/AKT pathway inhibitor LY294002. After $24 \mathrm{~h}$, the AKT and p-AKT-Ser473 levels were examined by western blot using anti-AKT, anti-p-Ser473 antibodies in cells transfected with vector, UEV1A with or without LY294002 treatment as indicated. Ectopic UEV1A expression was detected by an anti-HA-tag antibody. (C, D) Relative CT45A expression levels in MDA-MB-231 (C) and MCF7 (D) cells transfected with vector, UEV1A with or without LY294002 treatment as indicated, followed by qRT-PCR. (E, F) MDA- MB-231 (E) and MCF7 (F) cells were treated with IGF-1 over time as indicated and the cellular AKT and p-AKTSer473 proteins were monitored by western blot using anti-AKT and anti-p-AKT-Ser473 antibodies. $(G, H)$ The transcript levels of CT45A in MDA-MB-231 (G) and MCF7 (H) cells treated with IGF-1 over time were monitored by qRT-PCR. All experiments were performed in at least triplicate and the results are the average with standard deviation. **, $\mathrm{P}<0.01$. 
A

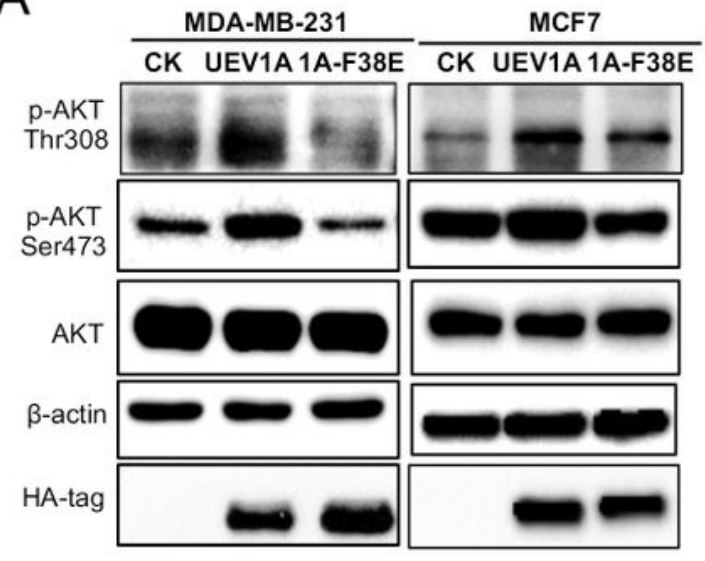

C

MDA-MB-231

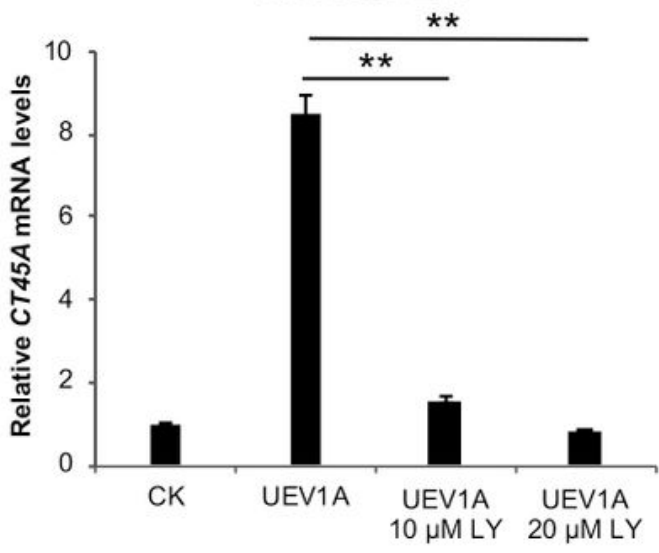

$E$

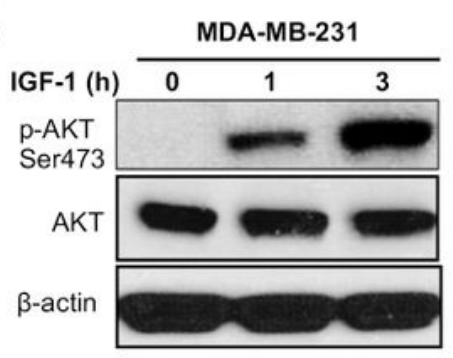

$\mathrm{F}$

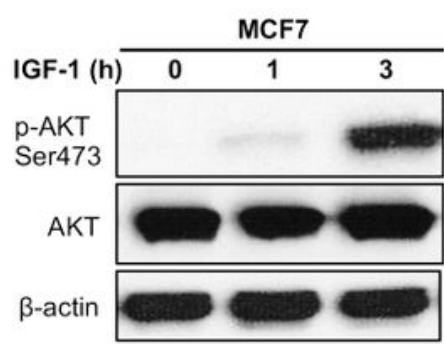

B

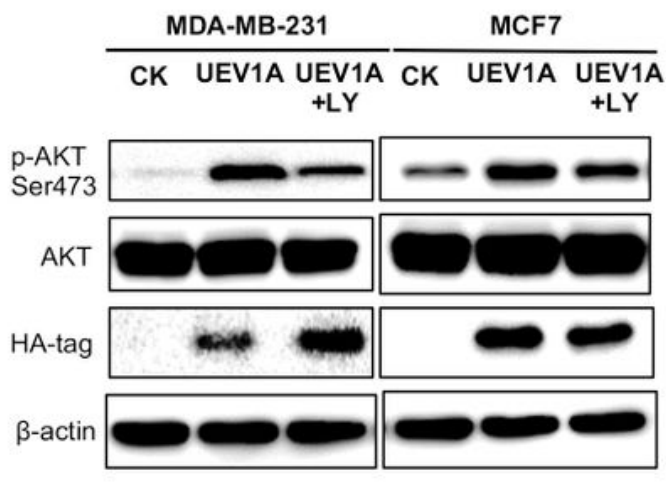

D

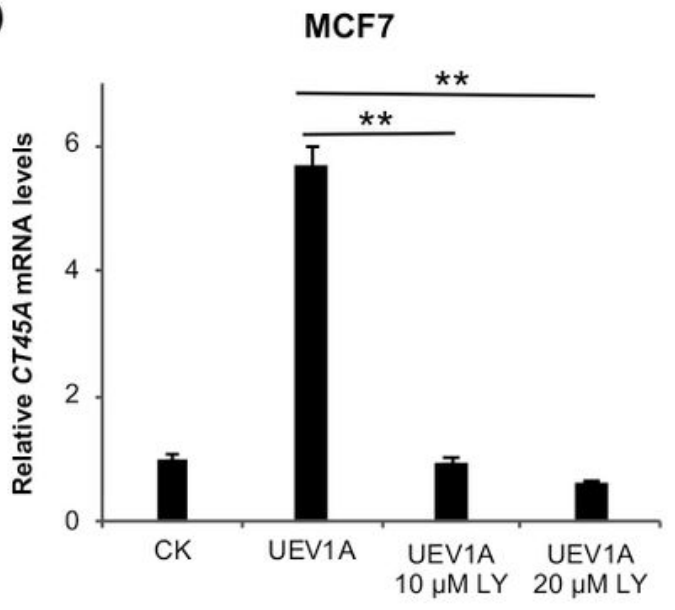

$\mathrm{H}$

MDA-MB-231
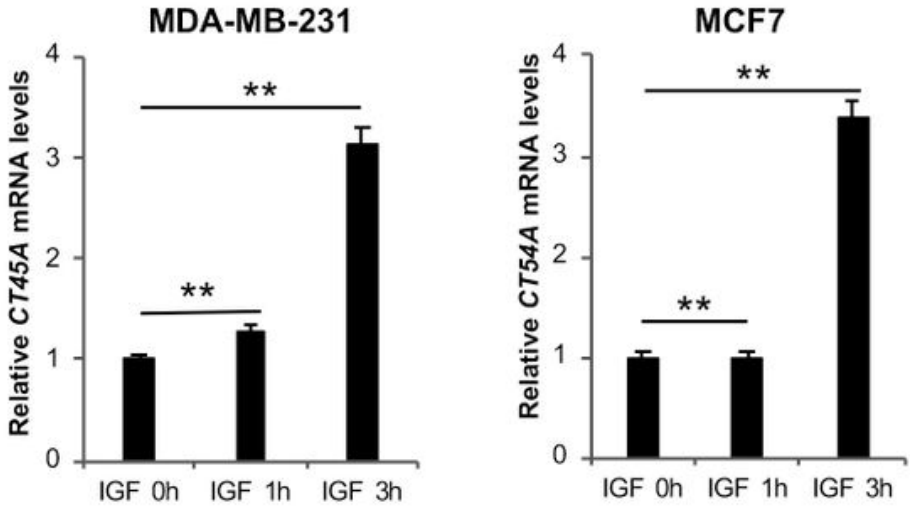

\section{Figure 7}

Uev1 A regulates CT45A expression through the AKT signaling pathway. (A) The cellular AKT protein and its phosphorylation (p-AKT-Thr308, p-AKT-Ser473) levels in pcDNA4.0/TO/HA (+) vector (CK), UEV1A, UEV1A-F38E transiently-transfected MDA-MB-231 (left panel) and MCF7 (right panel) cells were monitored by western blot using anti-AKT, anti-p-AKT-Thr308 and anti-p-AKT-Ser473 antibodies. (B) The UEV1A transiently-transfected MDA-MB-231 (left panel) and MCF7 (right panel) cells were treated with 10 
$\mu \mathrm{M}$ PI3K/AKT pathway inhibitor LY294002. After $24 \mathrm{~h}$, the AKT and p-AKT-Ser473 levels were examined by western blot using anti-AKT, anti-p-Ser473 antibodies in cells transfected with vector, UEV1A with or without LY294002 treatment as indicated. Ectopic UEV1A expression was detected by an anti-HA-tag antibody. (C, D) Relative CT45A expression levels in MDA-MB-231 (C) and MCF7 (D) cells transfected with vector, UEV1A with or without LY294002 treatment as indicated, followed by qRT-PCR. (E, F) MDA- MB-231 (E) and MCF7 (F) cells were treated with IGF-1 over time as indicated and the cellular AKT and p-AKTSer473 proteins were monitored by western blot using anti-AKT and anti-p-AKT-Ser473 antibodies. $(G, H)$ The transcript levels of CT45A in MDA-MB-231 (G) and MCF7 (H) cells treated with IGF-1 over time were monitored by qRT-PCR. All experiments were performed in at least triplicate and the results are the average with standard deviation. **, $\mathrm{P}<0.01$. 


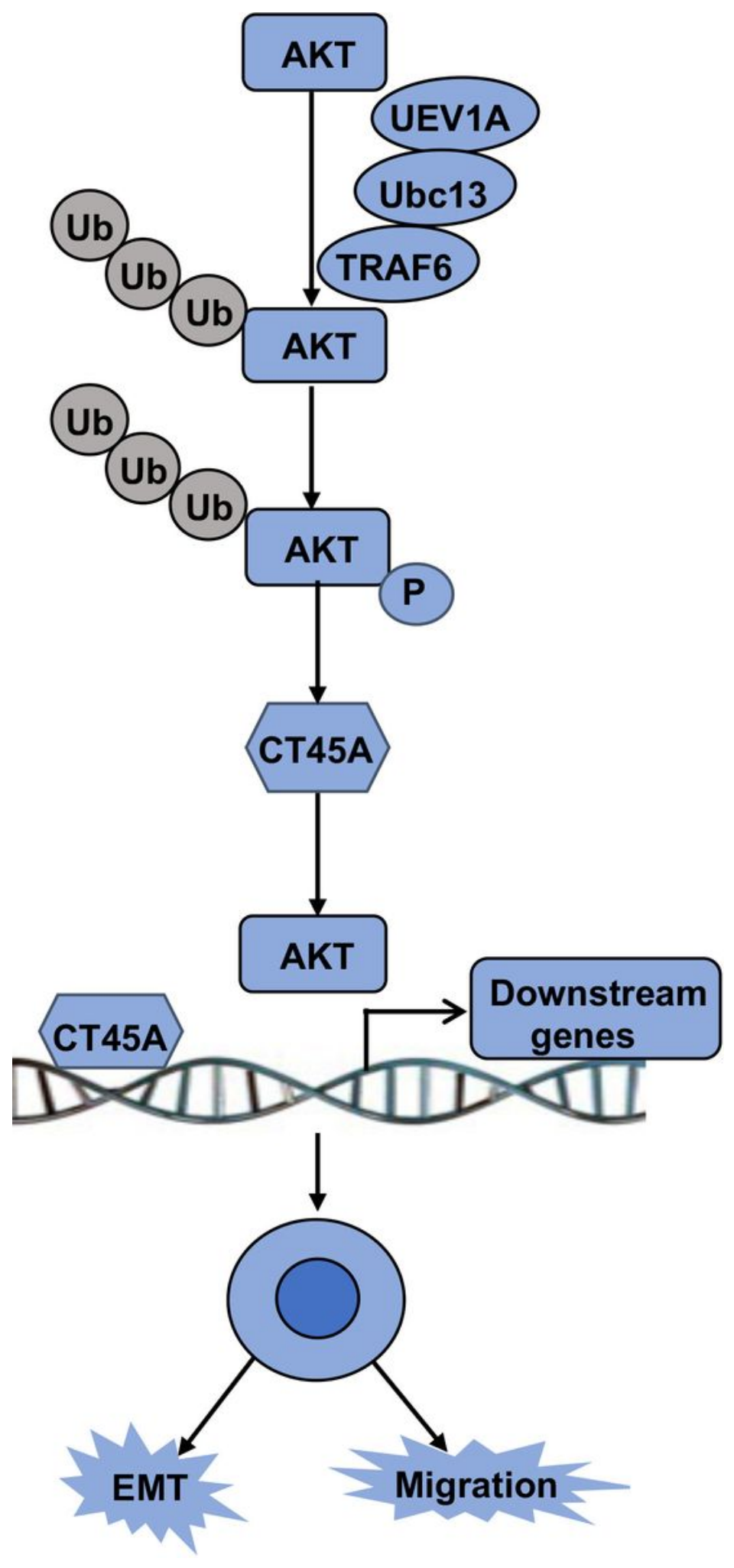

Figure 8

A proposed model in which Uev1A promotes cell migration and EMT through the Uev1A-AKT-CT45A axis in breast cancer. The Uev1A-Ubc13 complex (E2) together with TRAF6 (E3) ubiquitinate AKT, which is essential for AKT membrane localization, phosphorylation and activation. The phosphorylated and activated AKT positively regulates CT45A expression that in turn regulates the expression of the CT45A downstream genes, leading to increased cell migration and EMT in breast cancer. 


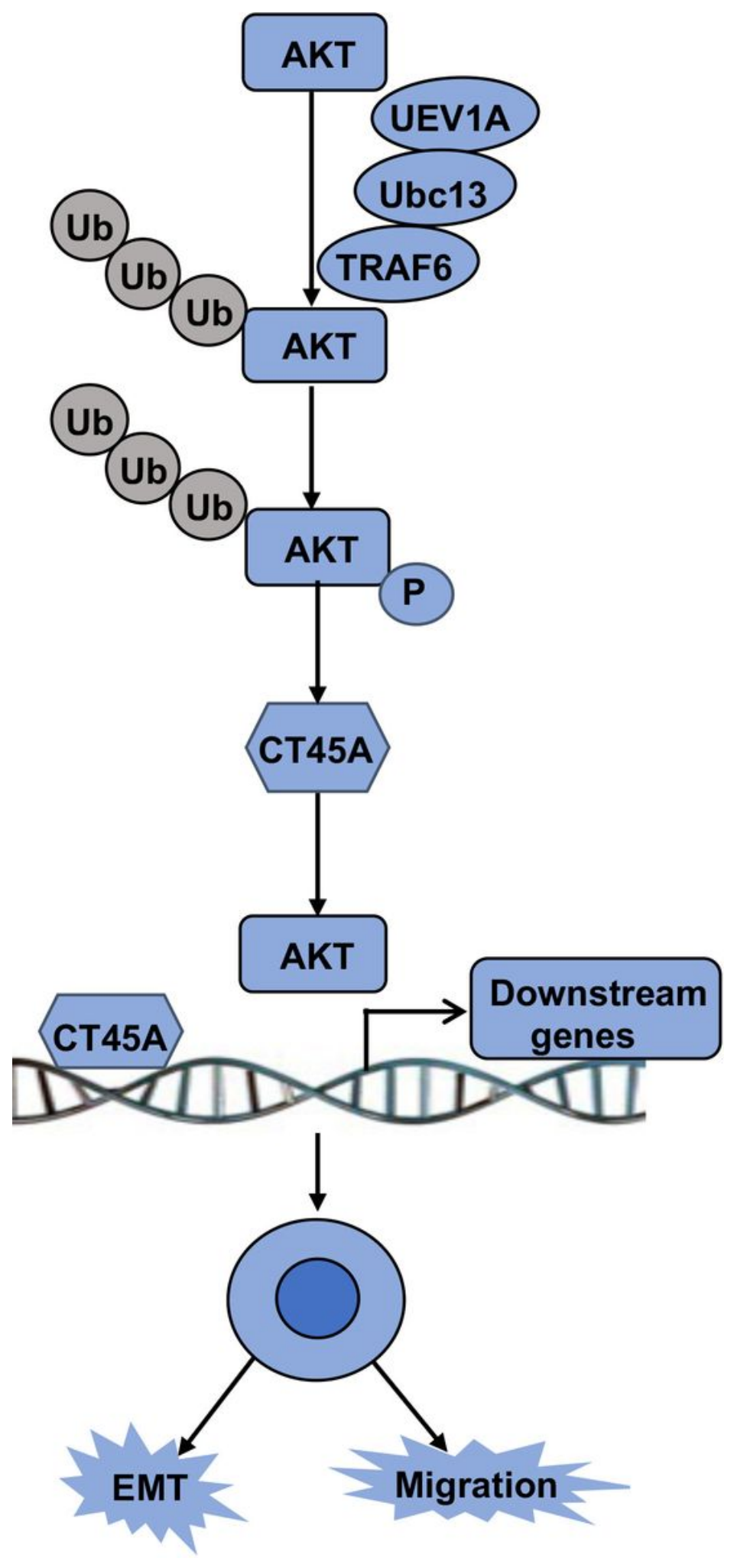

Figure 8

A proposed model in which Uev1A promotes cell migration and EMT through the Uev1A-AKT-CT45A axis in breast cancer. The Uev1A-Ubc13 complex (E2) together with TRAF6 (E3) ubiquitinate AKT, which is essential for AKT membrane localization, phosphorylation and activation. The phosphorylated and activated AKT positively regulates CT45A expression that in turn regulates the expression of the CT45A downstream genes, leading to increased cell migration and EMT in breast cancer. 


\section{Supplementary Files}

This is a list of supplementary files associated with this preprint. Click to download.

- UEV1ACT45ASupplementary.docx

- UEV1ACT45ASupplementary.docx 